Key Words: retrieval, tank heel, waste tank

Retention: Permanent

\title{
EM-31 RETRIEVAL KNOWLEDGE CENTER MEETING REPORT: MOBILIZE AND DISLODGE TANK WASTE HEELS
}
A.P. Fellinger ${ }^{1}$
M.W. Rinker ${ }^{2}$
R.L. Minichan ${ }^{1}$
J.L. Steimke ${ }^{1}$
K. Airhart ${ }^{2}$
${ }^{1}$ Savannah River National Laboratory
${ }^{2}$ Pacific Northwest National Laboratory

February 2010

Savannah River National Laboratory

Savannah River Nuclear Solutions

Aiken, SC 29808

Prepared for the U.S. Department of Energy under contract number DE-AC09-08SR22470. 


\section{DISCLAIMER}

This work was prepared under an agreement with and funded by the U.S. Government. Neither the U. S. Government or its employees, nor any of its contractors, subcontractors or their employees, makes any express or implied:

1. warranty or assumes any legal liability for the accuracy, completeness, or for the use or results of such use of any information, product, or process disclosed; or

2. representation that such use or results of such use would not infringe privately owned rights; or

3. endorsement or recommendation of any specifically identified commercial product, process, or service.

Any views and opinions of authors expressed in this work do not necessarily state or reflect those of the United States Government, or its contractors, or subcontractors.

Printed in the United States of America

Prepared for

U.S. Department of Energy 


\section{TABLE OF CONTENTS}

1.0 EXECUTIVE SUMMARY 5

$\begin{array}{ll}2.0 \text { INTRODUCTION } & 7\end{array}$

$\begin{array}{ll}2.1 \text { Background } & 7\end{array}$

2.2 Basic Retrieval Functions 7

3.0 THE GAPS AND CLOSING THE GAPS 9

3.1 The Gaps 9

3.2 Closing the Gaps $\quad 10$

4.0 SITE PRIORITIES 13

5.0 APPROACHES 15

5.1 Chemical Cleaning Approaches 15

5.2 Other Retrieval Approaches 16

5.2.1 Acid Dissolution 16

5.2.2 Modified Sluicing 16

5.2.3 Vacuum Retrieval 16

5.2.4 Saltcake Dissolution 16

5.2.5 Remote Water Lance (Salt Mantis) 17

5.2.6 Mobile Retrieval Tool (Sand Mantis) 17

5.2.7 Mobile Retrieval Tool (Foldtrack) 17

5.2.8 High Pressure Mixer (Rotary Viper) 17

5.2.9 Mobile Arm Retrieval System 18

6.0 CONCLUSION 19

$\begin{array}{ll}\text { 7.0 ATTACHMENTS } & 19\end{array}$

Attachment A: Proceedings of Dislodge/Mobilize Tank Waste Heel Workshop 20

Attachment B: NuVision Research on Commercial Dislodge/Mobilize Tank Waste Heel

Technologies 
This page intentionally left blank. 


\subsection{EXECUTIVE SUMMARY}

The Retrieval Knowledge Center sponsored a meeting in June 2009 to review challenges and gaps to retrieval of tank waste heels. The facilitated meeting was held at the Savannah River Research Campus with personnel broadly representing tank waste retrieval knowledge at Hanford, Savannah River, Idaho, and Oak Ridge. This document captures the results of this meeting.

In summary, it was agreed that the challenges to retrieval of tank waste heels fell into two broad categories: 1) mechanical heel waste retrieval methodologies and equipment and 2) understanding and manipulating the heel waste (physical, radiological, and chemical characteristics) to support retrieval options and subsequent processing. Recent successes and lessons from deployments of the Sand and Salt Mantis vehicles as well as retrieval of C-Area tanks at Hanford were reviewed.

Suggestions to address existing retrieval approaches that utilize a limited set of tools and techniques are included in this report. The meeting found that there had been very little effort to improve or integrate the multiple proven or new techniques and tools available into a menu of available methods for rapid insertion into baselines. It is recommended that focused developmental efforts continue in the two areas underway (low-level mixing evaluation and pumping slurries with large solid materials) and that projects to demonstrate new/improved tools be launched to outfit tank farm operators with the needed tools to complete tank heel retrievals effectively and efficiently. 
This page intentionally left blank. 


\subsection{INTRODUCTION}

This document describes the results of a meeting held on June 3, 2009 at the Savannah River Site in South Carolina to identify technology gaps and potential technology solutions to retrieving highlevel waste (HLW) heels from waste tanks within the complex of sites run by the U. S. Department of Energy (DOE). The meeting brought together personnel with extensive tank waste retrieval knowledge from DOE's four major waste sites--Hanford, Savannah River, Idaho, and Oak Ridge. The meeting was arranged by the Retrieval Knowledge Center (RKC), which is a technology development project sponsored by the Office of Technology Innovation \& Development - formerly the Office of Engineering and Technology - within the DOE Office of Environmental Management (EM).

\subsection{Background}

The DOE Complex has over two-hundred underground storage tanks containing over 80 million gallons of legacy waste from the production of nuclear weapons. The majority of the waste is located at four major sites across the nation and is planned for treatment over a period of almost forty years. The DOE-EM Office of Technology Innovation \& Development sponsors technology research and development programs to support processing advancements and technology maturation designed to improve the costs and schedule for disposal of the waste and closure of the tanks.

Within the FY09 waste processing program area are numerous technical initiatives, including the development of a suite of waste removal technologies to address the need for proven equipment and techniques to remove high-level radioactive wastes from waste tanks. In an effort to enhance the efficiency of waste retrieval operations, the DOE-EM Office of Technology Innovation \& Development funded the RKC to improve communications and information sharing regarding retrieval among the DOE's major waste tank locations. Since 2008, the RKC has been co-led by the Savannah River National Laboratory (SRNL) and the Pacific Northwest National Laboratory (PNNL) with core team membership representing the Oak Ridge and Idaho sites as well as site contractors responsible for waste tank operations. The RKC was projected ultimately to provide the venue for assembling information on new retrieval technologies and assessing state-of-the-art technologies applicable to retrieval needs within the complex.

\subsection{Basic Retrieval Functions}

The RKC has hosted a series of meetings designed to capture and evaluate the functions related to HLW tank retrieval as a means of determining specific technology areas as input to the larger DOEEM Technology Development Program¹. In April 2009, the RKC team issued a report titled "EM-21 Retrieval Knowledge Center: Waste Retrieval Challenges” (SRNL-STI-2009-00231, Reference 1) that resulted from meetings in late-2008 and captured the technical challenges of waste retrieval. The report describes technical challenges in the five primary functions of retrieval (characterize, access, dislodge/mobilize, convey and transport). The information generated from the 2008 meetings and documented in the report serves as a foundation for detailed review of specific retrieval functions to

\footnotetext{
${ }^{1}$ The Retrieval Knowledge Center hosted a series of meetings in late 2008 that identified high-level challenges to tank waste retrieval. These meetings prompted a more in-depth review of challenges in specific functions of retrieval in this case, dislodging and mobilizing tank waste heels.
} 
feed technology roadmapping and development plans to address the noted technical gaps collectively.

One of the greatest challenges to the processing and closure of many of the tanks is complete removal of all tank contents. Sizeable technical challenges not normally found with tank retrieval in commercial applications exist for retrieving waste from HLW tanks. Technologies currently in use for waste retrieval are generally adequate for bulk removal of liquids and slurries; however, removal of tank heels, the materials settled in the bottom of the tank, using the same technology has proven to be difficult

The RKC assembled a team of technical personnel broadly representing tank waste retrieval knowledge at Hanford, Savannah River, Idaho and Oak Ridge for a working meeting on June 3, 2009 at the Savannah River Site in Aiken, South Carolina, to discuss what has been attempted within the DOE Complex and across industry for retrieving tank heels. The team reviewed recent site heel retrieval deployments, such as SRS Tanks 18 and 19 Sand Mantis deployment and modified sluicing on Tank C-103 at Hanford. The facilitated meeting reviewed specific technologies and lessons as to why they worked or did not work. The meeting also discussed needs and gaps in technologies for retrieving tank heels and what might be possible (e.g., through similar applications in commercial industry) and what would be needed to make new options available. Areas such as keeping solids suspended at low tank levels; moving tank solids to, into, and through pumps; and characterizing waste were just three of the nine gaps that were reviewed. The team briefly reviewed industries that might help bridge the technical gaps discussed. 


\subsection{THE GAPS AND CLOSING THE GAPS}

\subsection{The Gaps}

A number of technical gaps for the retrieval function Dislodge/Mobilize Tank Heels were identified at the meeting. Sites have traditionally been successful with bulk waste retrieval; however, challenges in dealing with the residual waste after the bulk is removed still exist. Since many of the waste tanks are quite large there is a potential for a significant amount of waste to remain even at extremely low levels following bulk retrieval.

The meeting resolved that technical gaps for retrieval of tank heels could be broadly defined as, i) mechanical heel waste retrieval methodologies and equipment, and, ii) understanding and manipulating the heel waste characteristics to support retrieval and subsequent processes. The category of mechanical methodologies focuses primarily on technologies to get to the heel waste and get it to some means of conveyance out of the tank. The category of understanding and manipulating the characteristics of the heel waste stems from waste being left as the heel in a tank is likely not the same (physically and/or chemically) as the waste removed during bulk retrievals. Technologies to alter (in-situ or otherwise) the heel waste have not been aggressively explored for retrieval, in part because of reluctance to understand the heel waste characteristics. Table 1 describes the general technical gaps and challenges to heel retrieval discussed at the meeting, as well as, possible technology solutions.

Gaps that need to be addressed to facilitate the Dislodge/Mobilize function include particle size reduction, maintaining solids in suspension, low level mixing while dealing with in tank obstacles so ultimately solids are mobilized into a transfer pump for conveyance out of the tank. Potential solutions include the following: Using a grinder to reduce particle size with an independent unit or coupled with a pump. Improved mixing techniques at low tank levels $(<2 \mathrm{ft}$.) will facilitate the ability to maintain solids in suspension to simplify the process of pumping them out of a tank. An alternate technique involves mixing the tanks at higher levels (4-5ft) which is a proven technology while transferring the slurry to a receipt tank and circulating supernate back to minimize secondary waste.

Waste analysis is another area where many opportunities exist to develop a streamlined approach. Obtaining a representative sample and determining how much characterization is required are concerns that always come up in these discussions. The time to obtain analysis results due to handling of the radioactive samples and required analysis methods has the potential to impact closure schedules. As previously pointed out most of the challenges with retrieval are associated with the heel not bulk retrieval. Carefully planned analysis targeted to the challenging steps should prove to be more advantageous. Waste characterization of the heel to match solvents to the waste would likely make the chemical cleaning process more efficient. Another breakthrough in waste characterization can be made by developing specific field or tank top analysis methods that provide essentially instant results. 
Table 1. Technical gaps and challenges to tank waste heel retrieval.

\begin{tabular}{|c|c|c|}
\hline Category & Heel Retrieval Gap & $\begin{array}{c}\begin{array}{c}\text { Possible Technology Solution } \\
\text { Focus }\end{array} \\
\end{array}$ \\
\hline \multirow{5}{*}{$\begin{array}{l}\text { Mechanical heel } \\
\text { retrieval } \\
\text { technologies }\end{array}$} & $\begin{array}{l}\text { mating the heel solids to the pump } \\
\text { inlet }\end{array}$ & $\begin{array}{l}\text { crawlers and semi-autonomous } \\
\text { robots/manipulators that are able to } \\
\text { move the waste to the pump inlet or } \\
\text { move the pump inlet to the waste }\end{array}$ \\
\hline & solids suspension at low tank levels & low level mixers, flocculent \\
\hline & $\begin{array}{l}\text { heel retrieval in tanks with } \\
\text { obstructions (cooling coils, discarded } \\
\text { equipment, etc.) }\end{array}$ & $\begin{array}{l}\text { tandem pump/mixer process, } \\
\text { articulated sluicing }\end{array}$ \\
\hline & gaining access to the heel waste & $\begin{array}{l}\text { mechanical articulation or mobilization } \\
\text { using crawlers and semi-autonomous } \\
\text { robots/manipulators to go to the heel } \\
\text { waste }\end{array}$ \\
\hline & retrieval from leaking tanks & dry vacuum retrieval \\
\hline \multirow{4}{*}{$\begin{array}{l}\text { Heel } \\
\text { characterization }\end{array}$} & $\begin{array}{l}\text { adequate sampling and } \\
\text { characterization of the heel to support } \\
\text { process flow sheet validation }\end{array}$ & $\begin{array}{l}\text { in-situ gross analytical methods and } \\
\text { instruments, and analytical tools able to } \\
\text { access the heel waste }\end{array}$ \\
\hline & in-situ or in-line particle sizing & $\begin{array}{l}\text { grinders capable of being deployed in } \\
\text { tank or in-line to tailor particle sizes for } \\
\text { down stream processing }\end{array}$ \\
\hline & matching solvents with waste & $\begin{array}{l}\text { tailored solvent strategy for dealing } \\
\text { with tank heel waste }\end{array}$ \\
\hline & minimizing secondary waste & $\begin{array}{l}\text { Supernate recirculation / recycle } \\
\text { methodologies }\end{array}$ \\
\hline
\end{tabular}

\subsection{Closing the Gaps}

In reviewing the gaps there is a common theme of getting the solids mobilized to the transfer pump inlet for conveyed out of the tank.

Searches of commercial technologies have been performed over the years, but, a complete solution ("off-the-shelf”) has not been identified through these efforts. A search conducted for this meeting identified several categories of technology tools and methods including submerged jets, above surface nozzles, vacuums / pumps, grinders and enhanced chemical cleaning. Robotic crawlers and robotic arms were recognized as deployment technologies that can be used with any of the dislodge/mobilize techniques. In discussions of commercial technologies it was discovered that mining, sludge dredging and oceanographic are industries which have not been specifically investigated that have the potential to yield useful retrieval practices or ideas.

Due to the fact that there are a number of different tank types across the DOE complex, it is unlikely that a one size fits all solution exists. The differences are not only in the size and configuration but also in the waste form. Most SRS tanks have cooling coils inside the tanks which limit access to the entire tank. In some case there are dead zones (areas of very limited (or no) mixing) during the 
mixing process which cause solids to settle and even accumulate in these areas. Hanford waste tends to solidify and become hard over time presenting a different, but equally complex problem.

To close the gaps oriented towards physically maneuvering the waste in the tank towards conveyance systems would require development of technologies in two areas.

1) Development of technologies/tools that would be able to move to, and manipulate, the waste in the tank using crawlers and robotic platforms to deploy an array of tools (sluicers, jets, shovel/plow implements, etc.) to break-up and corral the waste towards the conveyance system). Tank farm operators have had some successes in this area with the recent deployments of the FoldTrack Crawler and the Salt and Sand Mantis vehicles at both Hanford and SRS, however, the development of modular tool sets for these platforms would provide more flexibility in these systems. Development of a smaller, more robust and reliable platform with limited (or no) tether would improve the ability to employ proven tools in tanks with obstructions.

2) Development of a platform and system design to move the pump inlet to the waste. This development effort could capitalize on existing proven vehicle platforms and focus the development effort on hose control and suction.

To close gaps oriented towards understanding the waste characteristics and the need for processes and techniques to manipulate the waste without water requires a concentrated initiative to develop in-line and remotely deployable instruments and analysis methods inside the tank.

Two efforts, underway within the RKC, are designed to demonstrate potential solutions for specific gaps. A task commissioned at SRS through the RKC is designed to evaluate potential concepts for low level mixing, while at the Hanford site, the RKC is developing a strategy to demonstrate pumping slurries with large solid materials. This demonstration program could be expanded into alternatives on the same theme or with other technology ideas to promote the advancement or combination of technologies/ tools which could solve additional gaps.

It is also notable that promising opportunities exist with improvements to existing technologies that could be expected to return dividends with further development. Some are simply enhancements to proven retrieval techniques while others are more novel concepts. The magnitude of the waste retrieval scope expected to be executed within the next 5-10 years warrants focus of resources to further develop these promising retrieval technologies, if for no other reason, for efficiency. The cost to develop and demonstrate retrieval techniques continues to pale in comparison to failed attempts or less efficient retrieval evolutions with actual waste in the tank. 
This page intentionally left blank.

12 of 53 


\subsection{SITE PRIORITIES}

Savannah River and Hanford tank farm priorities are integral to planned approaches for retrieving waste from aging waste tanks to support the EM Cleanup mission. In efforts to expedite the tank retrieval and processing, the baseline approaches have capitalized on new or improved technologies and techniques where possible. As of this meeting, both sites have committed to System Plan updates that describe the priorities and approaches to aggressively pursuing tank closures. ${ }^{2}$

The Savannah River Site has recently reported the goal to close (e.g., grout) up to twenty-two tanks in the next eight years. This goal assumes appropriate levels of funding, and is supported by the following priorities:

o Grout Tanks 5, 6, 18 and 19. Previously the tanks had been emptied and chemically cleaned,

o Complete bulk waste removal from Tanks 4, 7 and 8, and heel removal from Tank 4 followed by chemical cleaning and then grouting all three,

o Clean the annulus of Tank 16 and grout the tank,

o Perform bulk waste removal on Tanks 9, 10, 11, 12, 13, 14, 15 and 22 followed by enhanced chemical cleaning and grouting,

o Perform bulk waste removal on Tank 21 followed by enhanced chemical cleaning and grout Tank 21 following a period of about 3-years as interim lag storage,

o Perform bulk waste removal on Tanks 23 and 24 followed by mechanical cleaning and then grouting.

\footnotetext{
2 The latest SRS and Hanford System Plans should be used for the most accurate and up-to-date information on site
} priorities for tank retrievals and processing. 
This page intentionally left blank. 


\subsection{APPROACHES}

Difficult-to-remove waste deposits, limited accessibility, in-tank debris, and obstructions, all present particular technical complexities to site goals. Bulk waste retrieval that leaves varying chemical and physical compositions (i.e. different size, shape, consistency) of waste behind (as both the tank and residue coatings) could lead to materials that are not acceptable for downstream processing. Additionally, a number of tanks are known to have leaked in the past, which limits the use of current technologies that require the addition of significant volumes of water (i.e. sluicing).

The Savannah River has described approaches that capitalizes on both existing (chemical cleaning) and new (enhanced chemical cleaning) technologies to address tank retrieval goals. However, these approaches may not be appropriate in every case, particularly in the heel retrievals of the Type I and Type II tanks, where cooling coils and other in-tank obstructions may hinder deployment of these technologies without changes, ultimately necessitating continued investigation into alternatives that may be quickly and reliably inserted into retrieval plans when needed.

\subsection{Chemical Cleaning Approaches}

Mechanical cleaning often cannot remove remaining residual waste prior to tank closure, requiring chemical cleaning to dissolve and remove the final residual tank waste. Applying chemical cleaning technologies requires that consideration be given to tank integrity and the impact of residual chemicals on downstream processes. Also a sizeable fraction (nominally 5000 gallons) of slurry remains distributed among a maze of cooling coils in Savannah River Site (SRS) waste tanks after bulk removal. Heel removal is required for tanks which are targeted for closure and the tank chemical cleaning concept involves the removal of these heels by chemical dissolution, although it is feasible that some suspended insoluble solids may also be removed in subsequent waste transfers. At SRS, baseline chemical cleaning technology utilizes high amounts of oxalic acid which causes downstream impacts.

The enhanced chemical cleaning option focuses on the removal of radioactive sludge slurry heels remaining in waste tanks at the completion of mechanical sludge removal campaigns. And while it is preferred that a technology be identified which is applicable to heel removal operations for waste tanks at both SRS and Hanford, the given range of waste compositions existing in the tanks, it is unlikely that a single treatment technology can be used in all tanks. Rather, a suite of technologies will likely by needed with the preferred technology for a given tank depending upon the waste composition involved.

The focus of the Alternative Enhanced Chemical Cleaning Program is to identify and evaluate alternatives to the baseline SRS chemical cleaning technology ( $8 \mathrm{wt}$. \% oxalic acid) and further the understanding of the chemistry involved with the most promising methods. Oxalic acid is generally considered to be the cleaning agent of choice for the removal of tank heels, but oxalate ion has significant downstream processing impacts. Nonetheless, the baseline process has not been optimized to minimize the addition of oxalate to the tank farm. Oxalate minimization can occur by decreasing the amount of reagent added for dissolution or by destroying the oxalate prior to transfer to the receipt tank. Due to changes in the requirements and expectations for tank chemical cleaning methods and the desire to develop a number of tools for heel removal there was a need to reevaluate the alternative technologies. As a result, a Literature Review was conducted which built upon 
previous published reviews. Based upon the results of the review, a Systems Engineering Evaluation (SEE) was conducted to identify areas considered worthy of further study. Two separate rankings were performed in the SEE which focused on 1) alternative chemical cleaning technologies/reagents, and 2) organic oxidation technologies (primarily oxalate). Work is expected to continue in this area to identify alternatives to chemical cleaning of waste tanks.

\subsection{Other Retrieval Approaches}

Other retrieval technologies have been developed and matured to a point that they are included in site baselines for waste retrieval. These technologies, "the nine-retrieval technologies"3 have been described as the foundation for retrieval at Hanford and SRS.

\subsubsection{Acid Dissolution}

Oxalic acid dissolution was developed and used for removal of waste from Hanford's C-106 tank. Acid dissolution (oxalic and other) technologies are fairly mature, but typically require tailoring to specific waste types, and since dissolution can increase waste volumes, the technology can be limiting when deployed in waste tank applications.

\subsubsection{Modified Sluicing}

Modified sluicing uses high pressure water or liquid radioactive waste sprayed from nozzles above the waste. The liquid dissolves and/or mobilizes the waste so it can be pumped and removed from the tank. Modified sluicing would typically be deployed using a mast and 2-4 degrees of articulation. Sluicing has been used at both SRS and Hanford. Recent efforts at Hanford employed modifiedsluicing retrieval on Tanks C-108, C-109, and C-110. Retrieval of waste from single-shell tank C110 resumed this past January removing approximately 90 percent of the waste using modified sluicing. It is believed that modified sluicing has reached the limits of the technology to remove any further waste from this tank. Tank C-110 is a 530,000 gallon tank, built in 1946, and held approximately 126,000 gallons of sludge and other radioactive and chemical waste materials prior to retrieval. The modified sluicing technology used liquid waste from a nearby double-shell tank to break up, dissolve and mobilize the solid material so it can be pumped. Because of the variety of waste, sluicing is often not able to remove all of the waste, however, the technology is well-proven and available for use on tanks to remove heel materials.

\subsubsection{Vacuum Retrieval}

Vacuum retrieval is comprised of several types (and modifications) of lifting wastes out of tanks using pumps, jet eductors, etc. Hanford has used Vacuum Retrieval to successfully remove wastes from C-204, C-201, C-202, and C-203.

\subsubsection{Saltcake Dissolution}

Saltcake Dissolution as a retrieval technology is well understood and proven (dissolving of salts using water or waste tank supernate). Water additions for dissolution have been historically driven based on pump constraints, corrosion inhibitor requirements, and sludge transfer target concentration of 8 wt. \% (or lower, as necessary). The amount of supernate generated from salt dissolution is generally determined by assuming that 1.93 gallons of water will dissolve one gallon of saltcake for a combined final volume of 2.8 gallons. Methods for using wash water, DWPF recycle, supernate,

\footnotetext{
${ }^{3}$ The "nine-retrieval technologies" term was derived in discussions between Office of River Protection and EM Headquarters in planning for FY2010 Technology Development and Deployment Program.
} 
etc. to reduce the volume demand (tank space) have been considered. In general saltcake dissolution technology is mature and well understood, however, flow-sheet alternatives (i.e. DWPF recycle) need further testing before ready for deployment.

\subsubsection{Remote Water Lance (Salt Mantis)}

The Salt Mantis is a commercial (TMR Associates, Denver, CO), tethered crawler outfitted with a high pressure / low flow water jet (lance) capable of breaking up packed wastes. The fixed high pressure lance sprays wastes to break (dislodge) and mix packed wastes to move it towards pump inlets deployed in tandem with the crawler. The Salt Mantis was deployed at Hanford's S-112 tank in combination with other retrieval technologies to remove waste. The technology is proven and available for use on other tanks.

\subsubsection{Mobile Retrieval Tool (Sand Mantis)}

The Sand Mantis is a commercial (TMR Associates, Denver, CO), tethered crawler (based on the crawler platform of the Salt Mantis) outfitted with a high pressure / low flow eductor for lifting (vacuuming) solids. The crawler used 26-32 psi water nozzle(s) to create adequate vacuum to remove material from a source tank and propel the material to a receipt tank. The Sand Mantis demonstrated a capability to transfer material through approximately 500 - 600 feet of 2" hose with a 53 foot lift during cold testing. The Sand Mantis also included a plow and lower pressure water jets mounted at the front of the platform. The equipment has been deployed at SRS Tanks 18 and 19 to breakup and remove residual materials (heels). The deployment efforts at SRS included a fairly extensive deployment of a hose-in-hose transfer line and necessary shielding, and grinding equipment used at the receipt tank to reduce the particle size of the Zeolite material to less than 38 microns. The mechanical cleaning system was operated on both tanks for less than 500 hours each and resulted in preliminary approximations of about one-thousand gallons of remaining solids in each tank. The technology is proven and available for use on tanks with little or no obstructions to remove heel materials.

\subsubsection{Mobile Retrieval Tool (Foldtrack)}

The FoldTrack Crawler is a mobile tether retrieval tool which can be installed in the tank through a 12” Schedule 40 riser and can mechanically break-up and push the waste to the slurry pump. Water jets installed on the tool also aid in mobilizing the solids. The Fold track was installed at Hanford in April 2008 after extensive testing and used for retrieval operations at Hanford's C-109 Tank. However, shortly after deployment in C-109, the crawler threw one of the tracks used for movement shortly after deployment. System improvements and design modifications as well as lessons resulting from the effort have been reviewed. The technology has been deployed in at least one DOE waste tank, and with modifications for robustness and reliability would be immediately deployable in other tanks.

\subsubsection{High Pressure Mixer (Rotary Viper)}

The Rotary Viper is an ultra-high pressure mixer capable of mixing high viscosity wastes. The technology employs a sluicer and high pressure jets in a rotating pattern to mix wastes. The shaft mounted equipment is height -adjustable and deployed through a 4” riser. The Rotary Viper was used on Hanford's S-102 for partial removal of the waste. The technology is mature and available for use (but is typically most effective when combined with other retrieval technologies). 


\subsubsection{Mobile Arm Retrieval System}

The Mobile Arm Retrieval System (MARS) is an extendable robotic arm outfitted with a waste pumping system that features a vacuum (for assumed leaking tanks) and pumping system (centrifugal pump) for sluicing-type operations. The arm is controlled by operators using state-ofthe-art controllers and video systems. The system is comprised of a telescoping, robotic arm with a pump on a central mast, and a system of high-pressure water nozzles at the end of the arm and fits through a 42" riser. The arm is capable of using its elbow-joint movement, plus its multi-axle wrist movements to reach around obstacles. Depending on the type of waste, MARS is estimated to be able to remove waste at rates from 85 gpm up to nearly 1000 gallons per hour. MARS is undergoing testing and is planned for initial use in a Hanford's C-107 tank. 


\subsection{CONCLUSION}

The June $3^{\text {rd }}$, 2009 RKC meeting resolved that technical gaps to retrieval of tank heels could be broadly described as; i) mechanical heel waste retrieval methodologies and equipment, and, ii) understanding and manipulating the heel waste characteristics to support retrieval and subsequent processes.

While site retrieval approaches utilize a limited set of sound tools and techniques, there has been very little effort to improve or integrate the multiple proven or new techniques and tools available into a menu of available methods for rapid insertion into baselines. It is recommended that focused developmental efforts continue in the two areas underway (low-level mixing evaluation and pumping slurries with large solid materials) and efforts to demonstrate new/improved tools be launched to arm the tank farm operators with the needed tools to complete tank heel retrievals effectively and efficiently.

\subsection{ATTACHMENTS}

A. EM-21 Retrieval Knowledge Center (RKC) Dislodge/Mobilize Tank Waste Heel Strategic Planning Workshop - June 3, 2009

B. NuVision Research on Commercial Dislodge/Mobilize Tank Waste Heel Technologies 


\title{
EM-21 Retrieval Knowledge Center (RKC) Dislodge/Mobilize Tank Waste Heel Strategic Planning Workshop
}

\author{
June 3, 2009
}

Savannah River Site, Aiken County Research Park

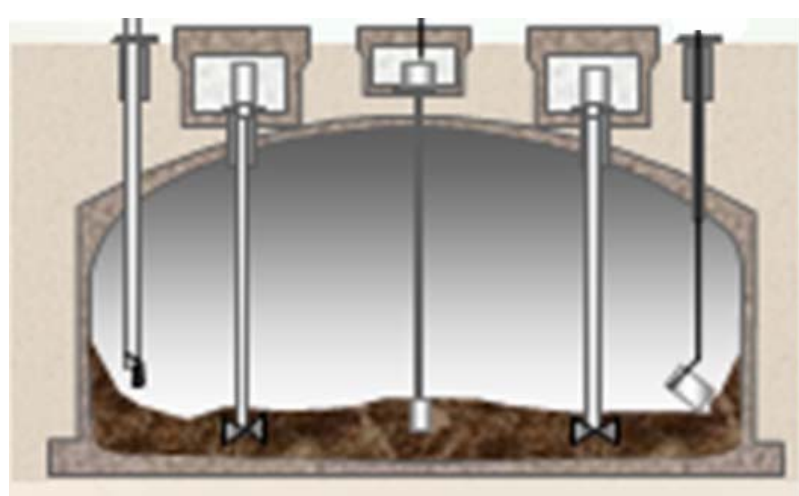

Requested by: $\quad$ Drew Fellinger, Savannah River National Laboratory and Mike Rinker, Pacific Northwest National Laboratory

EM-21 RKC Program Leaders

Facilitated by:

Richard A. Harrington, CVS-Life

CH2M HILL

Richland, Washington 


\section{TABLE OF CONTENTS}

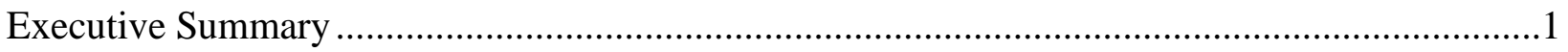

Appendices

A.Path Forward Action Items and Site Priority Retrieval Tanks. .3

B.Heel Retrieval Technical Gaps/Challenges.........................................................................

C.Heel Retrieval Technology Lessons ..........................................................................................

D. Industry Technologies Available, Program Plan Outline, \& Parking-Lot Information..............12

E. Workshop Agenda, Guidelines/Expectations, Opening Remarks \& Attendance Roster ...........14 


\section{EXECUTIVE SUMMARY}

EM-21 is the Waste Processing division of the Office of Engineering and Technology (OET), within the U.S. Department of Energy's (DOE's) Office of Environmental Management (EM). In August of 2008, EM-21 began a Retrieval and Closure initiative to develop a Retrieval Knowledge Center (RKC) Strategy and work plan. Part of this effort focuses on a tank waste retrieval scope lead by Andrew Fellinger of Savannah River National Laboratory (SRNL) and Mike Rinker of Pacific Northwest National Laboratory (PNNL). In support of this effort, two facilitated workshops were conducted in the fall of 2008 to define top-level retrieval requirements, challenges, lessons learned, and a path forward to support the EM-21 strategic business plan. The results of these workshops were summarized and documented in the EM-21 RKC Waste Retrieval Challenges report (PNNL18356/SRNL-STI-2009-00231).

On June 3, 2009, a third EM-21 RKC facilitated strategic planning workshop was conducted, at the SRNL's Aiken County Research Park, with a specific retrieval focus on Dislodge/Mobilize Tank Waste Heel. The objective was to develop the foundation (technology lessons, requirements, and gaps) and path forward to support a Tank Heel Retrieval strategic plan and future work. The multidisciplinary team members represented retrieval technology, operations, and engineering personnel from Savannah River, Hanford, Oak Ridge, Idaho Falls, and EM-21. Appendix E contains the workshop session agenda, opening remarks, guidelines and expectations, and attendance roster.

\section{Workshop Results}

The team was successfully developed a three-point path forward based on the 2010-2015 priority retrieval tanks by site (Appendix A), and a priority listing of Technical Gaps/Challenges (Appendix B) to be resolved. Additionally, Heel Retrieval Technology Lessons (Appendix C) were defined and supported by a listing of current industry technologies available, key requirements, and various future retrieval considerations (Appendix D) in support of the EM-21 RKC Program Strategy and Business Plan.

In summary, the path forward was developed to 1. Obtain additional technologies available from mining, sludge dredging, and oceanographic industries; 2. Identify analytical tools for use with robotic systems; and 3. Publish the Light Duty Utility Arm (LDUA) lessons learned in program play. The future tank retrievals were defined as Hanford and Savannah River priorities over the next five to eight years which was a key input in defining the priority rank Heel Retrieval Technical Gaps/Challenges. The foundation of these results was the detailed definition of Heel Retrieval Technology Lessons which answered the question of what has worked, what didn't work, and why; coupled with listing of key requirements and considerations for future successful tank heel retrievals at Savannah River and Hanford.

\section{Session Process}

The facilitator opened with the session purpose, agenda, safety topic, and team member introductions. Drew Fellinger and Mike Rinker delivered opening remarks which centered on tank heel retrieval (Dislodge/Mobilize) technology needs based on the technical gaps/challenges to be resolved in support of future retrieval priorities at both Hanford and Savannah River sites. In addition, while the team was asked to focus not on design needs but rather clear definition of the priority gaps/challenges to resolve if they were King or Queen for the day. Special thanks were also 
given to the multidisciplinary team members for their support and active participation in this workshop; to build off the previous workshops while focusing Tank Heel Retrievals.

Following the opening remarks, the facilitator led the team in defining the Technology Lessons Learned by site. Lessons were first defined as what has worked and why; followed by what didn't work why. Considerable dialogue evolved from the teams input and understanding of the why responses to what technologies worked and what didn't. Throughout this process any supplemental information, such as memories (i.e., retrieval ideas, interface considerations, and additional needs), and/or definitions were recorded on flipcharts (a.k.a., parking-lot sheets) for recall and confirmation prior to developing the path forward. In addition, any item of significant importance was denoted by a "flag-note" symbol (ß) for quick visual reference.

Upon completion of the technology lessons, the team reviewed and commented on a list of current industry technologies provided by the NuVision participants. This effort transitioned directly into the definition of the key requirements for future tank waste heel retrievals. The definition of technical gaps/challenges followed and naturally evolved from the aforementioned lessons, key requirements, industry available technologies and parking-lot information. The technical gaps followed a two step process: First, each team member defined their top level technical gap, which in-turn was offered offer up to the balance of the team to liquidate all questions to ensure understanding of each technical gap/challenge listed to be resolved. A total of nine technical gaps/challenges were identified. The second step involved each team members input to prioritize/rank the nine gaps/challenges using a Nominal Group Technique (NGT) process. The top four Technical Gaps/Challenges were:

1. Get solids to and through the pump, conveyance, and transport systems.

2. Keep solids suspended at low tank levels

3. Achieve maximum extent possible of waste removed in tanks with obstructions

4. Access the waste heel (with or without in tank obstructions)

Following the NGT, the team reviewed these ranking results and was engaged for any thoughts or observations. In brief, the team recognized that there are more in-tank obstructions at Savannah River than Hanford; Hanford has different waste sources; and these results may have been different if the focus was on one site, however it was also recognized that each member was asked input based on ownership for all tank retrievals and as if they were King or Queen for a day: What technical gaps if resolved would have most significant impact in successful heel retrieval?

The last agenda item included validation of parking-lot information and subsequent development of the three-point path forward. The session concluded with a round robin close-out where each member was engaged for any last minute items and meeting utility. One item addressed was to keep in mind the Hanford current initiative and need to deploy robotic manipulators to achieve tank retrievals. In summary, the team felt the workshop was value-added.

\section{Facilitator Comments}

The team did an excellent job of staying focused on dislodging and mobilizing tank waste heels. Throughout the workshop considerable and important dialogue included, but was not limited to, the need for analytical tools, phased characterization, and minimizing secondary waste. As with the two previous workshops, this team was senior-level professionals who represented actual tank waste 
retrieval operations experience and the collective lessons from four DOE sites. Special thanks to Drew Fellinger and Marie Layton for hosting this workshop and coordinating the workshop logistics which is critical to the success of any technical workshop. 


\section{APPENDIX A}

\section{PATH FORWARD ACTION ITEMS \\ AND SITE PRIORITY RETRIEVAL TANKS}

\begin{tabular}{|l|l|l|c|}
\hline \multicolumn{2}{|c|}{ PATH FORWARD ACTIONS } & \multicolumn{1}{|c|}{ Who } \\
\hline $\mathbf{1}$ & $\begin{array}{l}\text { Obtain technology lessons from mining, sludge } \\
\text { dredging, oceanographic, etc }\end{array}$ & $\begin{array}{l}\text { Erich Keszler \& } \\
\text { Talmadge Griffie }\end{array}$ & TBA \\
\hline $\mathbf{2}$ & $\begin{array}{l}\text { Consider/identify potential analytical tools in/out } \\
\text { of tank with robotic systems }\end{array}$ & $\begin{array}{l}\text { Mike Rinker \& Drew } \\
\text { Fellinger }\end{array}$ & TBA, In Progress \\
\hline $\mathbf{3}$ & $\begin{array}{l}\text { Define/consider/address Light Duty Utility Arm } \\
\text { (LDUA) success lessons in the program play }\end{array}$ & $\begin{array}{l}\text { Mike Rinker, Mark } \\
\text { Noakes, Julie Tripp, } \\
\text { \& Drew Fellinger }\end{array}$ & TBA \\
\hline
\end{tabular}

\section{PRIORITY RETRIEVAL TANKS 2010 - 2015}

- Savannah River Site: 12 -22 over next 8 years

- $\quad 80 \%$ of tanks have obstructions

- 3 tanks are salt, 14 are sludge

- All F Area tanks (10), not currently retrieved; H-Area 9 through 12 and 22 - 24

\section{- Hanford}

- C Farm (ten tanks)

- *C-105

- C-101

- C-102

- C-107

- C-111

- C-112

- C-104

- C-108, 109 and 110, which are tanks currently in progress

* = This retrieval will be a drier system 


\section{APPENDIX B}

\section{HEEL RETRIEVAL TECHNICAL GAPS/CHALLENGES}

\section{TECHNICAL GAPS/CHALLENGES}

1. Get solids into and through the pump, conveyance, and transport systems

1A. Move pump inlet to the waste

2. Keeping solids suspended at low tank levels

3. Achieving the Maximum Extent Possible (MEP) of waste removal in tanks with obstructions (e.g., Economic means to remove obstructions)

4. Getting/access to the waste heel

- With or without obstructions

5. Representative sample and adequate characterization

- Including process flow sheet validation

6. Particle size reduction

7. Matching solvent with waste

8. Minimize secondary waste

9. Retrieval from leaking tanks

Nominal Group Technique (NGT) Ranking

\begin{tabular}{|c|l|c|c|c|}
\hline Item & \multicolumn{1}{|c|}{ Votes/Points } & Votes & Points & New Rank \\
\hline $\mathbf{1}$ & $5,2,2,2,5,5,1,2,4,5,5,5,3,1,4$ & 15 & 51 & $\mathbf{1}$ \\
\hline $\mathbf{2}$ & $2,4,4,4,5,4,5,3,3,2,3,2,3,3$ & 14 & 47 & $\mathbf{2}$ \\
\hline $\mathbf{3}$ & $2,3,5,5,5,5,4,5,5$ & 9 & 39 & $\mathbf{3}$ \\
\hline $\mathbf{4}$ & $4,2,3,5,3,3,4,3,4,1,2$ & 11 & 34 & $\mathbf{4}$ \\
\hline $\mathbf{5}$ & $1,4,2,2,1,4,1,5,1$ & 9 & 21 & $\mathbf{5}$ \\
\hline $\mathbf{6}$ & $3,2,1,4,1$ & 5 & 11 & 7 \\
\hline $\mathbf{7}$ & $1,3,2,4,3$ & 5 & 13 & $\mathbf{6}$ \\
\hline $\mathbf{8}$ & $2,3,1,1,1,1$ & 6 & 9 & $\mathbf{8}$ \\
\hline $\mathbf{9}$ & $1,1,4,1$ & 4 & 7 & $\mathbf{9}$ \\
\hline
\end{tabular}

\section{NGT RANKING THOUGHTS/OBSERVATIONS INPUT}

- Obstructions are key at Savannah River Site Reference \#3

- Hanford has different waste sources, and mixer pumps does better job at suspension

- May have different results if Savannah River Site, Hanford, Idaho National Laboratory and Oak Ridge National Laboratory voted separately 


\section{APPENDIX C}

\section{TANK WASTE HEEL TECHNOLOGY LESSONS}

- What Worked and Why

- What Didn't Work and Why

- General Lessons and Management Observations

\section{WHAT WORKED AT SAVANNAH RIVER SITE}

1. Sand Mantis

2. Submersible Mixing Pumps (SMPs) Sub transfer pumps (STPs)

3. Tank 16: Hot Oxalic Acid

4. Waste and acid lancing

5. High pressure rotating sluicing jets

6. Fire hose sluicing

\section{WHY DID IT WORK}

1. Sand Mantis - Used on tanks 18 and 19: Partial removal

- No obstructions (in tank), remote and flexible

- Used low volume water

- Moved pump to solids, then broke up the solids

2. SMP's with STP's on tanks 5 and 6 (type 1 tanks with cooling coils) - Partial removal

- Modified mixers, with larger powerful nozzles

- Product lubricated and cooled

$>$ Used the waste slurry

- Cleaning to certain radius

- Note: No coils, it may have cleaned the entire tank

3. Hot or acid on 16: Complete retrieval

_ Dissolved sludge compounds; components of sludge were broke down small enough to be sluiced/pumped out

4. Water and acid lancing on tank 6, partial removal

- Mobilized, local effect

5. High Pressure rotating sluicing, jet tanks 1-6, and 8 for complete removal

6. Fire hose sluicing on tank 17, partial removal which left the gravel

\section{WHAT WORKED AT THE HANFORD SITE}

1. Vacuum Retrieval

2. Cold Oxalic Acid (OA)

3. Past practice and modified sluicing

4. Salt Mantis

5. Fold track

6. Rotary vipers

7. Caustic carrier solution 


\section{WHY DID IT WORK}

1. Vacuum retrieval C-201-204 (20’ diameter tanks) Complete removal

- Access all areas of tanks took system to the waste

- Broke up the heel

2. Cold Oxalic Acid on C-106, Partial removal

- Reduced partial size to facilitate sluicing

3. Modified sluicing, on C-103, Complete removal

- Finished the job; mobilized waste to the pump

- Recycled carrier fluid

- One process for bulk and heel removal

4. Salt Mantis on S-112 Partial removal (had to follow with other technologies)

- Broke into small particles to the pump and dissolved most of the material

5. Fold track on C-108, Partial removal

- Push waste to the pump

6. Rotary viper on S-102, partial removal

- Mixed difficult high viscosity waste, local effect 10 radius

7. Caustic carrier solution on S-112 Complete removal: Last technology used and didn't require new equipment

\section{TECHNOLOGIES THAT WORKED AT OTHER SITES}

$>$ Oak Ridge National Laboratory

- Light Duty Utility Arm (LDUA) and end effectors

- Houdini and end effectors

$>$ Fernald and Oak Ridge National Laboratory:

- power fluidics

Idaho National Laboratory

- Wash and directional spray, LDUA, and some sluicers

\section{WHAT DIDN'T WORK AT SAVANNAH RIVER SITE}

1 Oxalic Acid/chemical cleaning of tank 16 annulus

2 Flygt Mixers

3 Oxalic Acid (OA) with no agitation

4 Sluicing on heavy gravel piles

5 Submersible Mixing Pumps at low levels, as presented used today

\section{WHY IT DIDN'T WORK}

1 Material was not soluble

2 Insufficient scouring velocity

3 Not enough contact with material and \#2 above (scouring)

4 Insufficient scouring velocity

5 Don't operate at low level and insufficient scouring velocity

\section{WHAT DIDN'T WORK AT HANFORD}

1 Modified sluicing

2 Ultra high pressure viper

3 Salt mantis 


\section{WHY IT DIDN'T WORK}

1 - Insufficient scouring velocity and conveyance

- Does not capture heavy particles in the conveyance system

- $\quad$ Limited effected radius

2 - Ultra high pressure viper

- $\quad$ Limited effected radius

- $\quad$ Limited carrier fluid

3 - Salt mantis

- Capture pump velocity was challenged/overcome

\section{GENERAL LESSONS}

$>$ Most of Hanford lessons stem from:

- Failure to capture the waste (heavy particulate) by the pump

$>$ Mobilize and convey all you want, but if it doesn't get into the suction pump/ it doesn't leave the tank.

$>$ Chemical processes attack specific waste forms and leave behind the radionuclides

- We can mobilize and convey and pump, but we cannot keep solids suspended at low level

Tank obstructions limit cleaning capability

\section{PROGRAM MANAGEMENT OBSERVATIONS}

- Obstructions are key at Savannah River Site.....Reference \#3

- Hanford has different waste sources and mixer pump does better job at suspension

- Might have been different if Savannah River Site, Hanford, Idaho National Laboratory and Oak Ridge National Laboratory voted separately 


\section{APPENDIX D}

\section{INDUSTRY TECHNOLOGIES AVAILABLE, PROGRAM PLAN OUTLINE AND PARKING LOT INFORMATION}

\section{Parking Lot Information}

- Key Requirements

- Definitions

- Memories

\section{INDUSTRY TECHNOLOGIES AVAILABLE}

- Current Non-DOE (Private sector) Industries, by general category

1. Submerged jets

- Potential solution to gap/challenge number 1, 2 and 6

2. Above surface nozzles

- Spray balls and nozzles

3. Robotic crawlers

- Potential solution to gap/challenge number 4 and 9

- Note: Platforms with various end effectors (See item 7 below)

4. Robotic Arms

- Potential solution to gap/challenge number 4 and 9

- Note: Platforms with various end effectors (See item 7 below)

5. Vacuums and pumps

- Potential solution to gap/challenge number 1, 6 and 9 at both sites

6. Enhanced chemical cleaning

- Potential solution to gap/challenge number 3, 4, 7, and 8

7. Cutting tools or grinders

\section{PROGRAM PLAN OUTLINE}

- Introduction

- History Lessons: Dislodge/Mobilize Waste

- What has been tried

- What worked and why

- What didn't work and why

- Baseline approach

- What retrieval tanks/farms in the next $0-5$ years

- What retrieval tanks/farms $>5$ years

- Requirements/Needs and Gaps

- How to address/solve gaps/challenges

- Results

- Conclusions

- References

ßNOTE: Consider a look ahead (beyond 5 years) section 


\section{KEY REQUIREMENTS}

- Minimize secondary waste

- Maintain Documented Safety Analysis

- Maintain tank integrity

- Containment, structural

- Corrosion

- Impact/cracking

- Detect leaks

- Remove waste

- Large particles (reduce particle size to convey)

- Low level suspension

- Get to pump (mobilize enough)

- Reduce particle size to convey

- Interface and compatibility with conveyance system and downstream facility/process (Including WAC)

- Compatible with “in-tank” obstructions: Remove or work around

- Access compatibility

- Meet closure requirements

- Define how clean

- Define equipment left behind conditions

- Best technology

- Monitor progress, know when you are done, end-state

- Characterization (phased approach)

- "The necessary and sufficient chemical, physical and rheology properties to dislodge/mobilize and convey tank waste (heel).”

\section{DEFINITIONS}

$>$ Tank Waste Heel

- Hanford post-sluicing is sand and gravel

$>$ Sand is sand

$>$ Gravel can be as small as pea gravel, and as large as 2" thick flagstone that might be 2' long or in diameter

- Savannah River Site post-Submersible Mixer Pump

$>$ Fluffy and suspendable (fluffable)

$>$ Outside the pump cleaning radius, the heel is compacted (clay like) with a yield of 100 to thousands Pascals

$>$ Gooey and sticky

$>$ Gravel (pear size or beach sand)

\section{MEMORIES}

- $\quad \sqrt{ }$ Savannah River Site: Tanks 18, 19, 5, and 6 are in process

- $\sqrt{ }$ Consider body of knowledge industries (Action Item \#1)

- Look outside DOE, such as mining, sludge dredging, etc...

- $\sqrt{ }$ Hanford heel is use based on sludge, not salt

- $\sqrt{ }$ Hot OA created 3 million gallons of secondary waste 
- $\sqrt{ }$ Vacuum retrieval created lots of secondary waste

- $\sqrt{ }$ Cold OA

- $\sqrt{ }$ Hard salt bake dissolves easily in the laboratory, not in the tank

- $\sqrt{ }$ Better analytical tools (Action Item \#2)

- $\sqrt{ }$ Consider localized heating to remove deposits (PS)

- $\sqrt{ }$ Solutions need to be integrated processes

$\sqrt{ }=$ Valid Memories 


\section{APPENDIX E}

WORKSHOP AGENDA, GUIDELINES AND EXPECTATIONS, OPENING REMARKS, AND ATTENDANCE ROSTER

\section{EM-21 RETRIEVAL KNOWLEDGE CENTER (RKC) DISLODGE/MOBILIZE TANK WASTE HEEL STRATEGIC PLANNING WORKSHOP}

\section{ACTL Building 999, Conference Room 101}

June 3, 2009

Purpose: Develop the foundation (technology lessons, requirements, and gaps) and path forward to support a Tank Heel Retrieval strategic business plan and future work

- Define heel retrieval lessons, requirements, and technical gaps/challenges

- Outline the program plan based on priority retrieval needs

- Develop the next steps and action required to proceed

\section{AGENDA}

8:00 - Welcome/Purpose, Safety Topic, and Introductions

- Review agenda, guidelines and expectations

- Opening Remarks: key drivers, success, and priority tanks

8:40 - Develop Tank Heel Technology Lessons

- Identify technologies used at SRS, Hanford, INL, and ORNL

- Define what worked, didn't work, and the why

- Utilize parking-lot sheets, as required (e.g. bulk retrieval ideas, impacts, interfaces)

10:00 - BREAK

10:15 - Define Heel Removal (Dislodge/Mobilize) Requirements

- Identify current industry technologies available

- Define upper level site functional requirements (e.g. end point criteria, interferences, etc.)

- Utilize parking-lot sheets, as required

\section{2:00 - WORKING LUNCH}

1:00 - Prioritize Technical Gaps/Challenges

- Identify site priority retrieval tanks

- Define technical gaps/challenges to be resolved

- Prioritize/rank gaps based on site retrieval and impacts

3:00 - BREAK 
3:15 - Develop Program Plan Outline and Path Forward

- Outline a Program Plan based on near and long term goals

- Identify follow-on needs and efforts needed (What and When)

- Define actions, as required (Who, What, and When) to proceed

5:00 - Finish Session with a Round Robin Closeout

- Last minute items

- Meeting Utility

\section{OPENING REMARKS}

- Build a program based on short and long term technology solution goals

- Thanks for your attendance, support and active participation

- Keys to success

- Technology needs based on gaps/challenge

- Completed two workshops last year that were successful in their focus

- Will build off these efforts

- Key is the people doing the heel removal

- Focus on the next 5-6 years

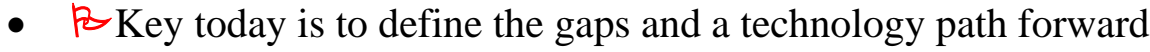

- Heel retrieval

- Savannah River Site: The last nominal 6", how do we deal with that and what are the issues

- Hanford: Great success with slurring, but then what are heel retrieval issues, gaps/challenges to be resolved

- Several people have been working in support of the Retrieval Knowledge Center program plan

- This workshop is a direct input and will influence this path forward

ß Note: Will not design; but do think if you were King or Queen for the day to resolve technical gaps/challenges

\section{GUIDELINES \& EXPECTATIONS}

- Open and honest communication

- Active listening

- Courage and consideration

- Be succinct.........make your point

- Lot of ground to cover

- No war stores

- Build off each other and maintain focus:

- Tank waste heel

- SRS and Hanford (Idaho National Laboratory and Oak Ridge National Laboratory

- Technology Lessons

- Savannah River Site and Hanford priority tanks

- $2010-2015$

- Technology gaps/challenges and needs

- Keys to success 
- Communication/Teamwork

- Define gaps/needs to be resolved

- Look for dual site opportunities

- Make a difference and have some fun along the way

\begin{tabular}{|c|c|c|c|}
\hline \multicolumn{4}{|c|}{$\begin{array}{r}\text { EM-21 RKC Dislodge/Mobilize Tank Waste Heel } \\
\text { Attendance Roster } \\
\text { June 3, } 2009\end{array}$} \\
\hline Name & Company & Phone & E-Mail \\
\hline Rudy Jolly & URS & $803-952-2604$ & rudolph.jolly@srs.gov \\
\hline Rick Minichan & SRNS & $803-725-2271$ & richard.minichan@srnl.doe.gov \\
\hline Dan McCabe & SRNS & 803-725-8238 & daniel.mccabe@srnl.doe.gov \\
\hline Mark Noakes & ORNL & $865-574-5695$ & noakesmw@ornl.gov \\
\hline Kelle Airhart & PNNL & $509-372-4797$ & kelleairhart@pnnl.gov \\
\hline Gary L. Smith & EM-21 & 509-376-0922 & gary.smith@em.doe.gov \\
\hline Mike Rinker & PNNL & $509-375-6623$ & mike.rinker@pnnl.gov \\
\hline Talmadge Griffie & NuVision & 704-799-2707 & griffie@nuvisioneng.com \\
\hline Erich Keszler & NuVision & 704-799-2707 & keszler@nuvisioneng.com \\
\hline Jake Venzie & SRNL & $803-725-4463$ & jacob.venzie@srnl.doe.gov \\
\hline Heather Burns & SRNL & 803-819-8497 & heather.burns@srnl.doe.gov \\
\hline Andrew Fellinger & SRNL & 803-725-5705 & A.fellinger@srnl.doe.gov \\
\hline Sharon Marra & SRNL & 803-725-5891 & sharon.marra@srnl.doe.gov \\
\hline Julie Tripp & INL & $208-526-3876$ & julia.tripp@inl.gov \\
\hline Kayle Boomer & WRPS & $509-372-3629$ & kayle.d.boomer@rl.gov \\
\hline Ruben Mendoza & WRPS & $509-372-2684$ & ruben_e_mendoza@rl.gov \\
\hline Richard Harrington & CH2M Hill & 509-372-9601 & richard_a_harrington@rl.gov \\
\hline Blaine Barton & WRPS & $509-376-5118$ & w_b_blaine_barton@rl.gov \\
\hline Marie Layton & SRNL & 803-725-1237 & marie.layton@srnl@doe.gov \\
\hline Tommy Caldwell & URS & $803-208-8430$ & Thomas.caldwell@srs.gov \\
\hline
\end{tabular}


Attachment B: NuVision Research on Commercial Dislodge/Mobilize Tank Waste Heel Technologies 


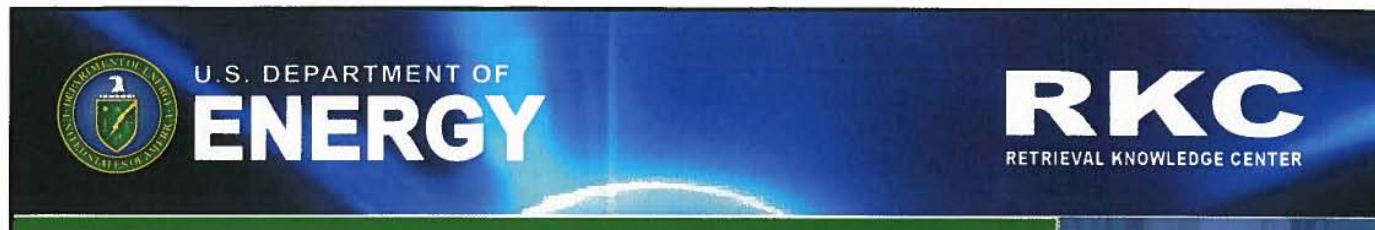

\section{Total Reclaim Systems}

\section{Industries}

Oil Companies, Service Companies and Drilling Contractors in The North Sea, the Netherlands, Norway and India. The majority of our business is carried out for 'Repeat Customers', indicating an appreciation of the cost and efficiency savings that Total Reclaim Systems deliver.

\section{History of Operations}

Total Reclaim Systems were formed in 1998, specifically to develop equipment and techniques which would greatly improve mud pit and tank cleaning on offshore oil rigs and production platforms.

Total Reclaim Systems designed and built a series of specialist air and electrically operated, jetting and vacuum pumps designed to pump heavy, solids and barite-laden hydrocarbon based fluids and slurries from mud pits. Our equipment and methodology reduces the volume of waste fluids created, reduces manual handling, ensures total containment and reduces personnel numbers involved in mud pit and tank cleaning operations.

\section{Nuclear Experience}

N/A

\section{Technical Approach}

One of the primary challenges that TRS faced while designing the PitGun was to develop a system that would minimise the volume of waste fluid required to clean. This has been made possible by recovering the residual dead volume of oil-based mud (OBM) via the Reclaim pumps high vertical suction capability. This fluid is then jetted through the pump and the specially designed nozzles. By doing so, solids are displaced from the pit walls, while any remaining solids on the tank floor are slurrified. The operator then uses the PitGun to direct the remaining slurry to special portable vacuum drum strainers that remove the waste material to a tote-tank, consolidation pit or vessel for removal. The operator fin ishes the job by thoroughly cleaning the tank interior with the PitGun. Cleaning fluid comprised of seawater and detergent is used, which may then be re-circulated and recovered by the Reclaim Pump Unit to further reduce the volume of wasté material.

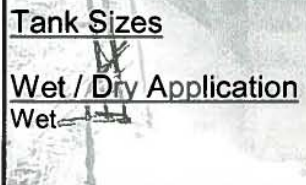




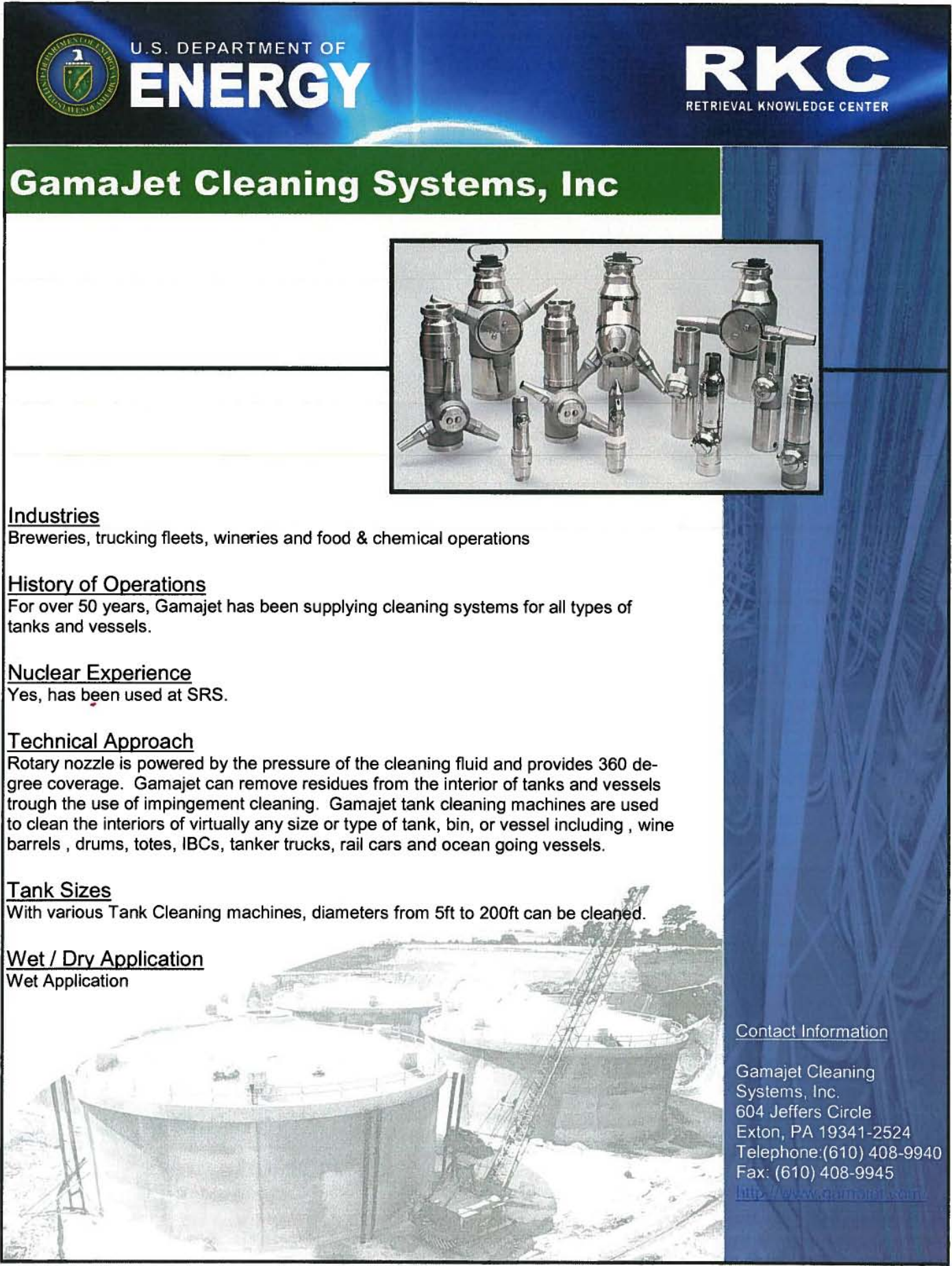




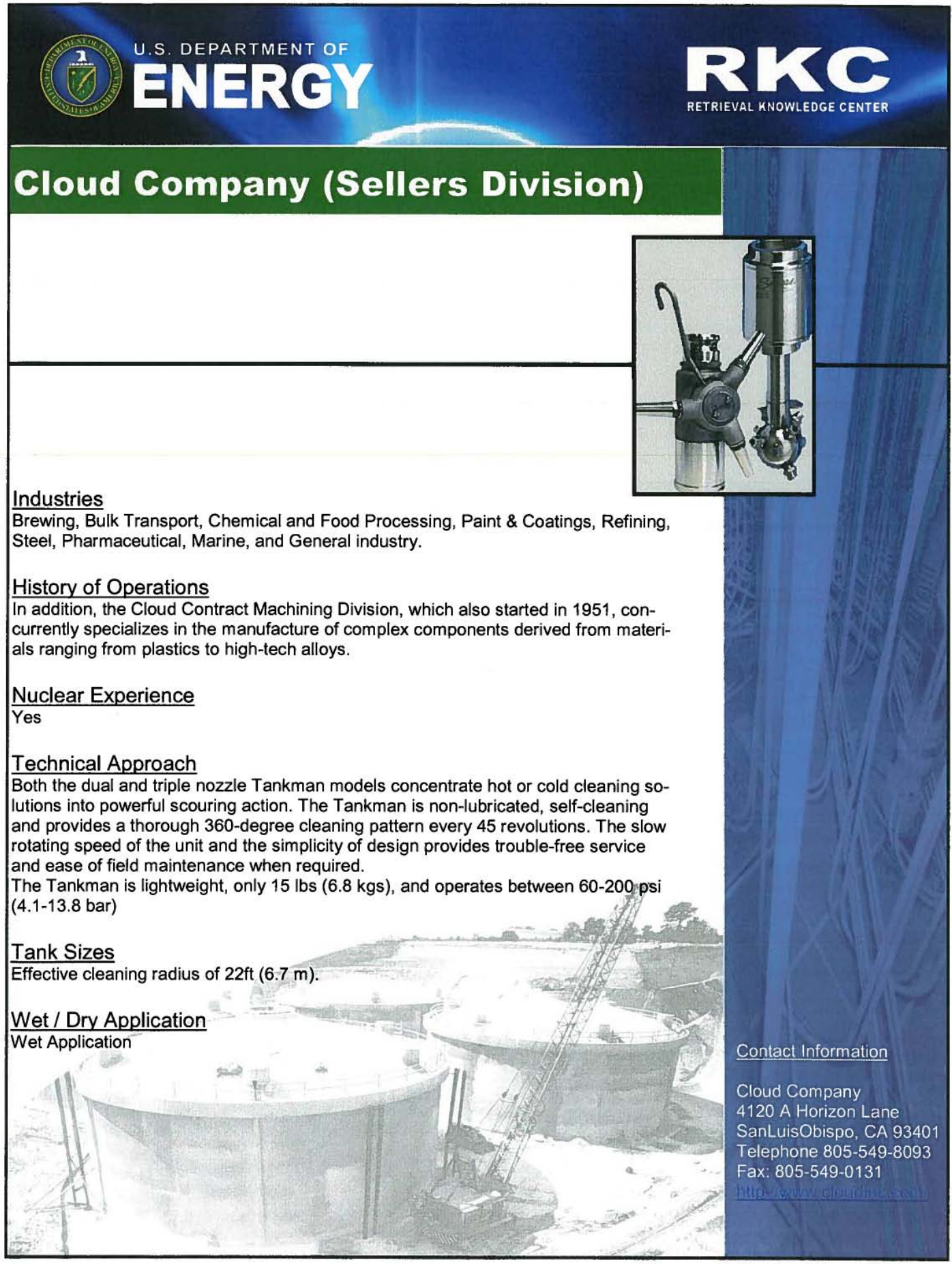




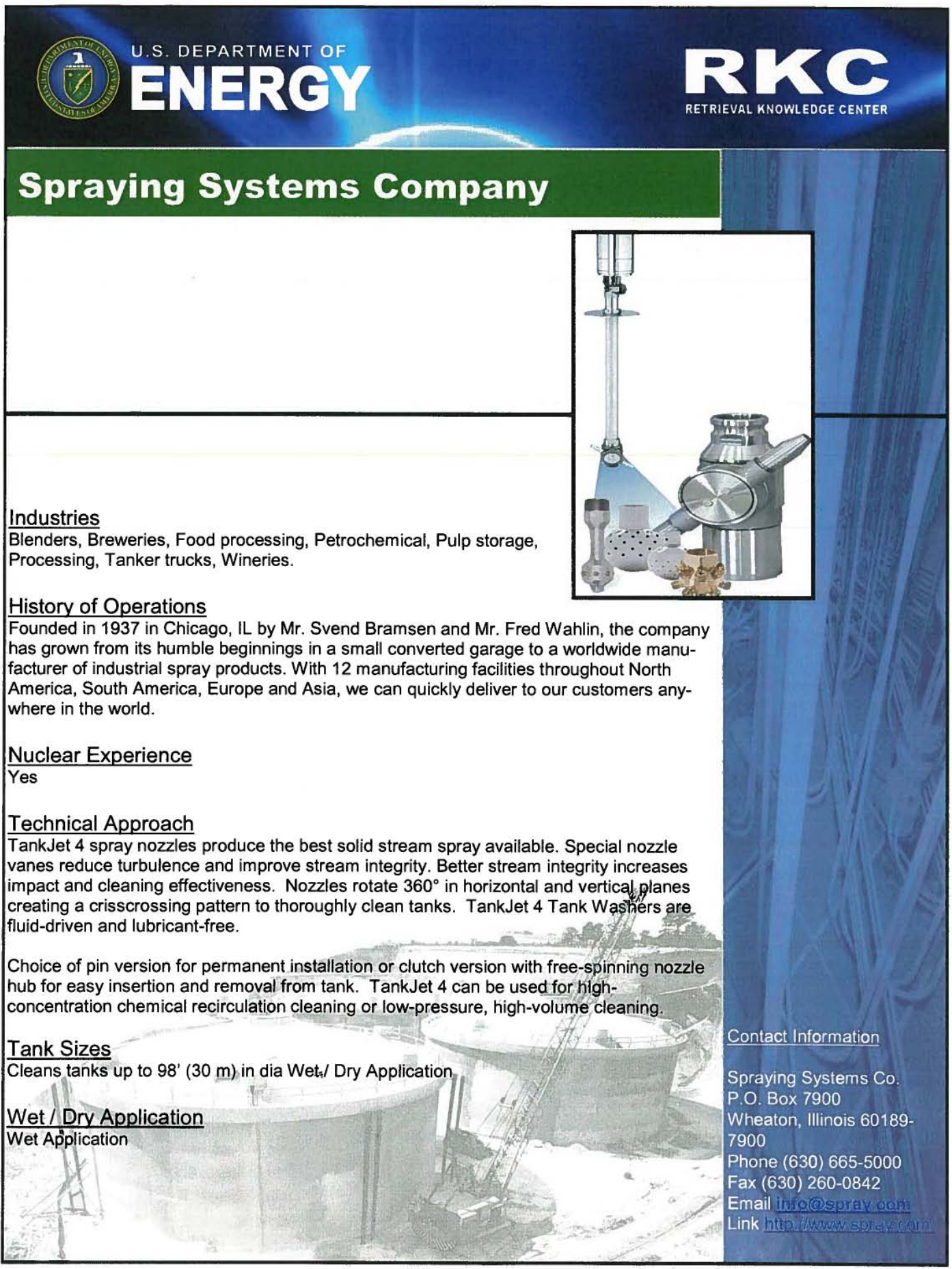




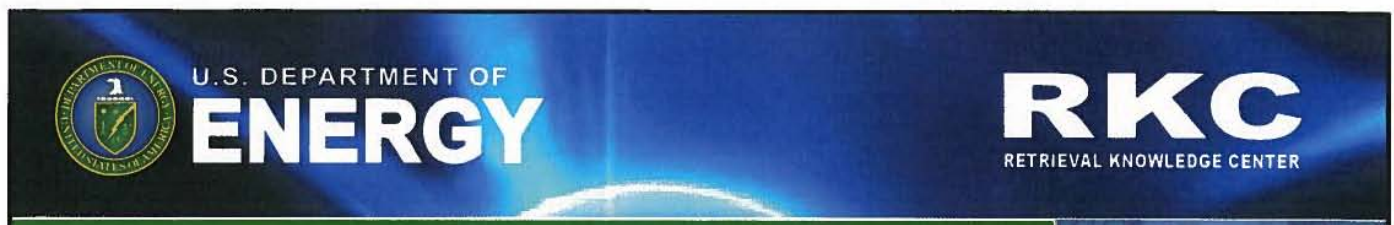

\section{Butterworth}

\section{Industries}

Ships, Barging, Offshore Drilling Rigs, Offshore Supply Boats, Contractors, Brewing, Pharmaceutical, Food, Energy,

Chemical Processing, Oil Refining, Transportation, Wineries,

Distilleries, Ethanol, Original Equipment Manufacturers, Beverage,

Pulp and Paper, Paints and Coatings, Waste Water

\section{History of Operations}

Arthur Butterworth, in 1920, patented the first Automated Tank Cleaning Machine and in

1925 the company was established to produce and market this revolutionary new product.

The company was subsequently sold to Standard Oil New Jersey (Exxon Corporation) in

1930 and remained an affiliated company until 1986. As part of an Exxon wide restructur-

ing program, Butterworth was sold to management in 1986 and is today privately held.

\section{Nuclear Experience}

Yes

\section{Technical Approach}

The Butterworth Type LTQ automated tank cleaning machine provides 360 degree impact indexed coverage for cleaning the inside of tanks and process vessels. Tank capacities range from 13,000 to 130,000 gallons ( $50-500$ cubic meters).

The Type LTQ machine creates a spray pattern matrix similar to a ball of twine. A complete pattern is established after 65 axial revolutions of the body have been completed. During the process of this pattern build out, 8 cycles are established with each cycle increasing the density of the pattern matrix.

Nozzle is fabricated from type 316 stainless steel and will fit through a 6.425 inch opening. Operational pressure is $300 \mathrm{psi}$, and operational temperature is $300 \mathrm{~F}$.

\section{Tank Sizes}

$0-72 \mathrm{FT}(22.0 \mathrm{M})$

Wet / Dry Application

Wet Application

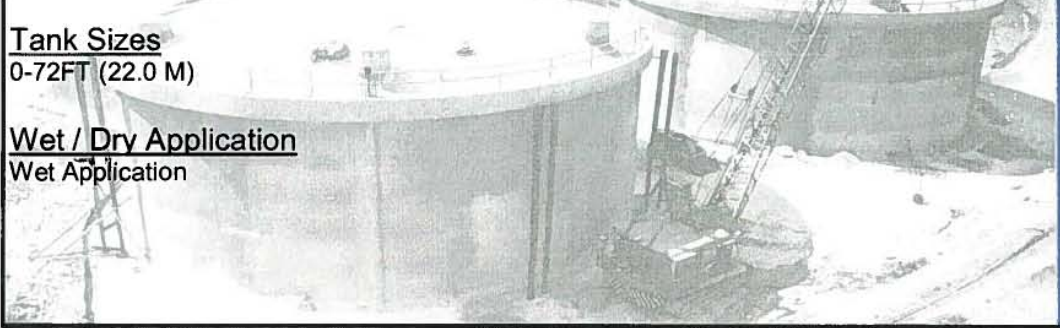



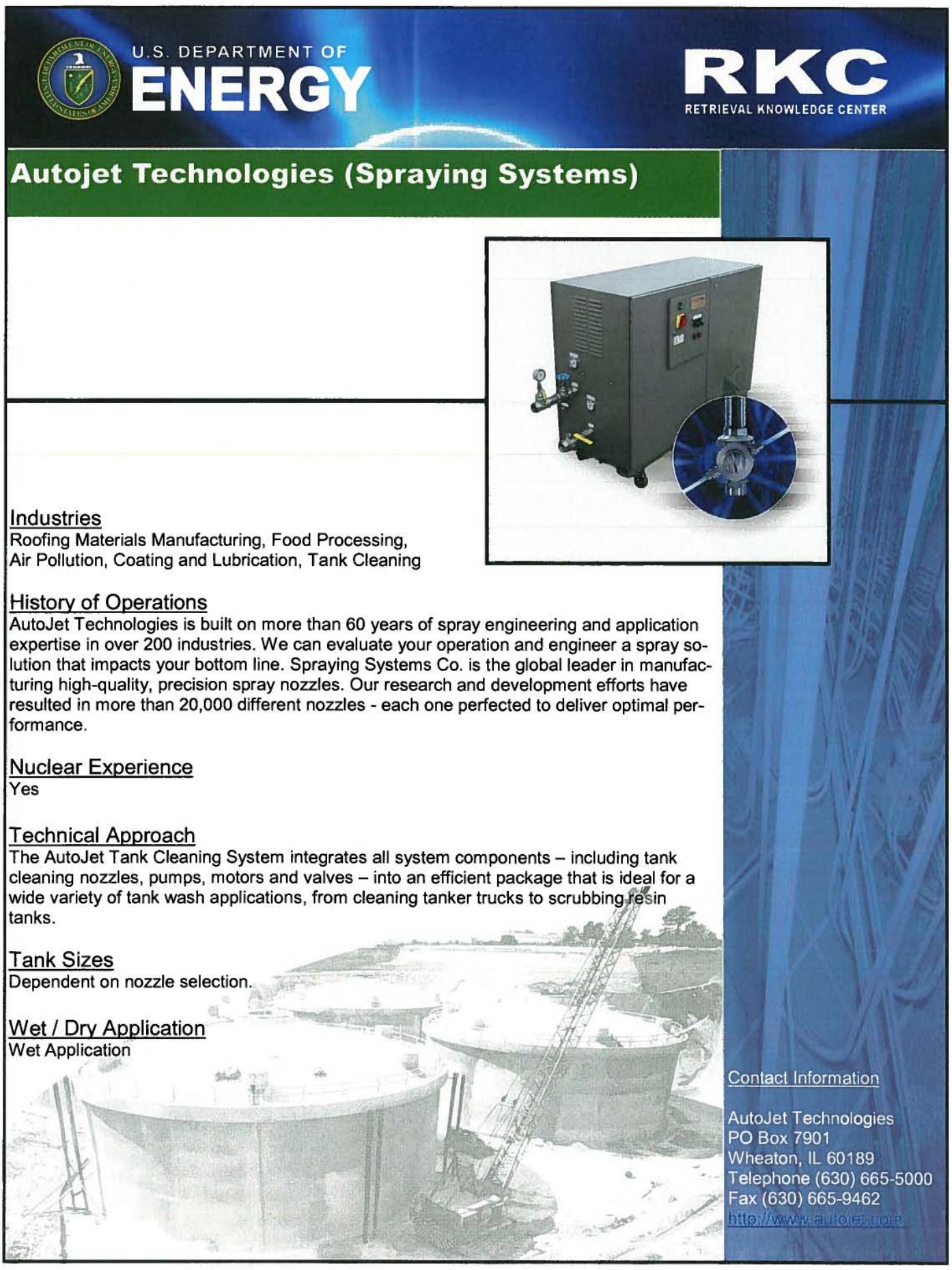


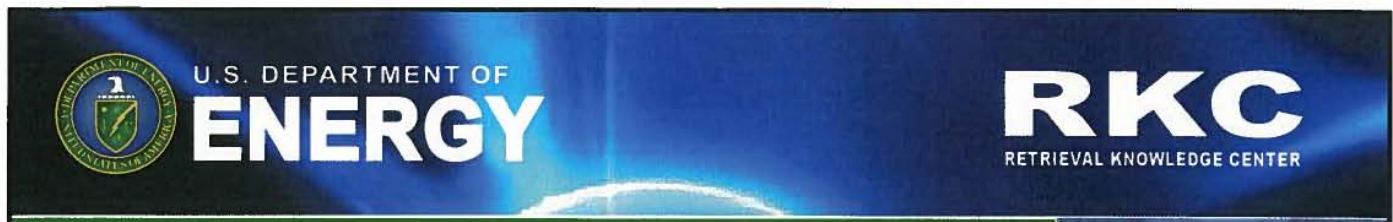

\section{Gould Stainless Products Ltd.}

\section{Industries}

The M-Series is specially designed for the wine,

food, beverage, dairy, chemical and pharmaceutical industries.

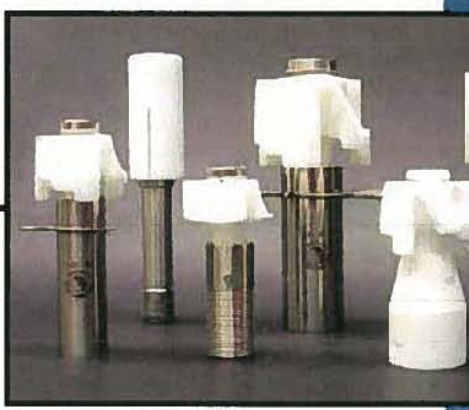

\section{History of Operations}

AutoJet Technologies is built on more than 60 years of spray engineering and application expertise in over 200 industries. We can evaluate your operation and engineer a spray solution that impacts your bottom line. Spraying Systems Co. is the global leader in manufacturing high-quality, precision spray nozzles. Our research and development efforts have resulted in more than 20,000 different nozzles - each one perfected to deliver optimal performance.

\section{Nuclear Experience}

\section{Technical Approach}

Designed with simplicity in mind, there are no bearings to lock-up, corrode or break down. The M-Series Tank Washer is powered by the cleaning fluid itself to rotate a unique patented mist-reducing head at a wide range of operating pressures. Reduction of spray mist allows the formation of larger spray droplets, which provides a higher degree of washing impact in comparison with competitive units. Its patented self-cleaning feature incorporates a downward wash-jet for cleaning centralized agitator units, and a cleaning stream that is also directed to the point of entry, top half and sides of tank for maximum cleaning effif ciency.

\section{Tank Sizes}

Dependent on nozzle selection.

\section{Wet / Dry Application}

Wet Application
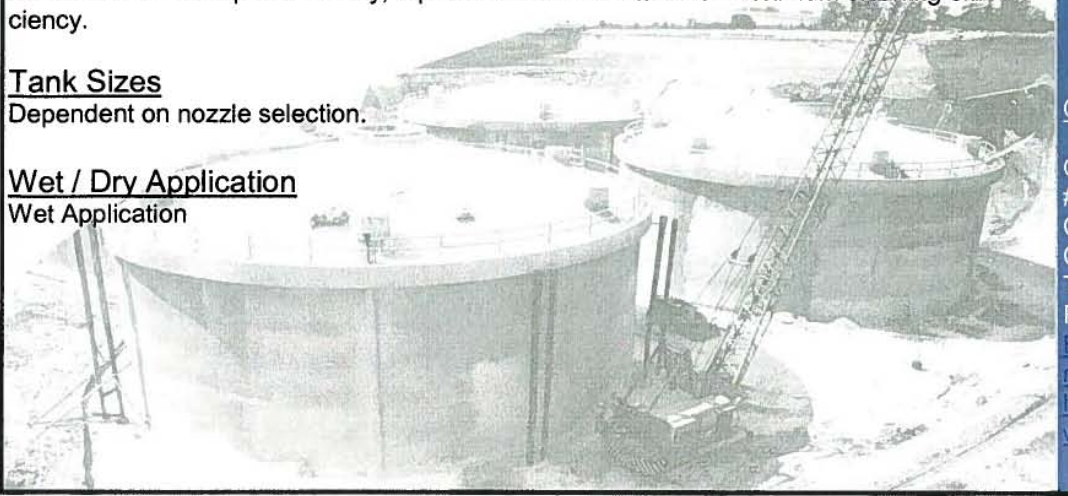


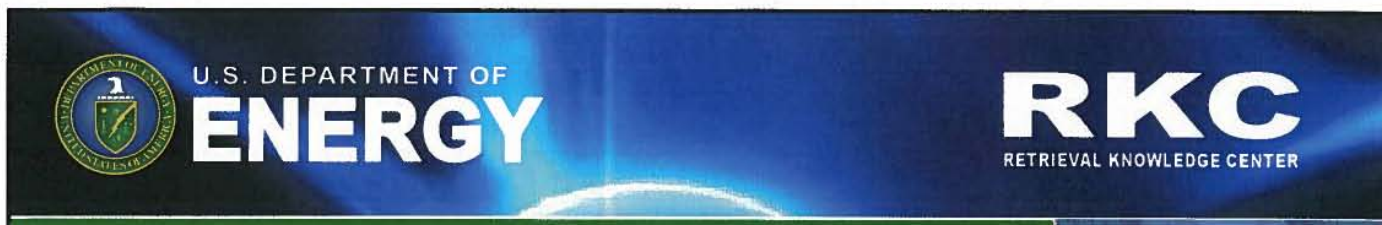

\section{Oreco A/S}

\section{Industries}

Tank Cleaning and Oil Recovery Processes

\section{History of Operations}

Oreco A/S develops, manufactures and globally markets mo-

bile, turnkey systems for automated waste oil recovery and storage tank cleaning in the oil and petrochemical industries. Oreco's systems offer a combination of oil tank cleaning with simultaneous separation of the cleaned-out sludge.

Tank cleaning and oil recovery services are offered through independent service providers. These service providers are members of the Oreco Partner network.

Oreco was formerly known as Toftejorg Technology A/S, which was founded in 1957.

\section{Nuclear Experience}

\section{Technical Approach}

BLABO process is specifically designed for cleaning crude oil tanks. System consists of multiple spray nozzles inside the crude tank and multiple skids of ancillary equipment to spray heated cleaning fluid.

The cleaning fluid is recirculated, centrifuged to remove sludge, filtered, and then reused. Solid waste separated is disposed.

\section{Tank Sizes}

Effective Throw length 14 - $22 \mathrm{~m}(46-72 \mathrm{ft})$

Wet / Dry Application Wet/Dry Application

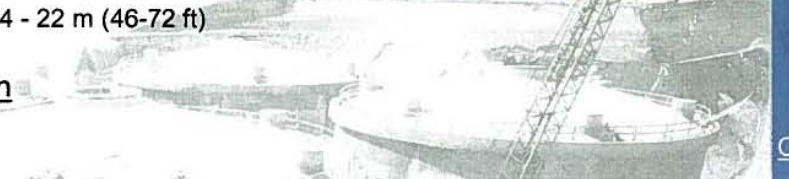




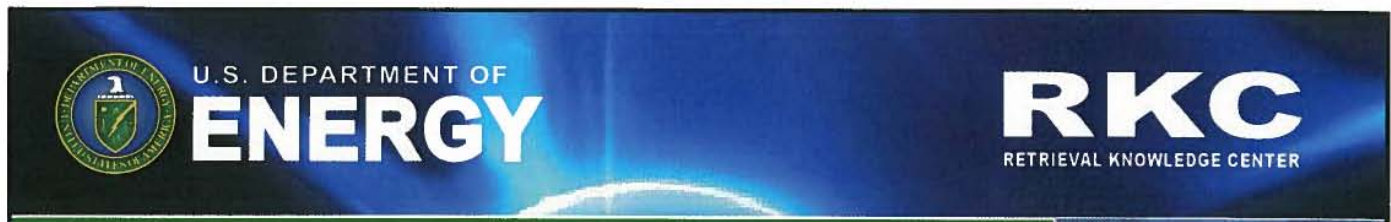

\section{Weda Water}

\section{Industries}

Tank Cleaning (Water Reservoirs)

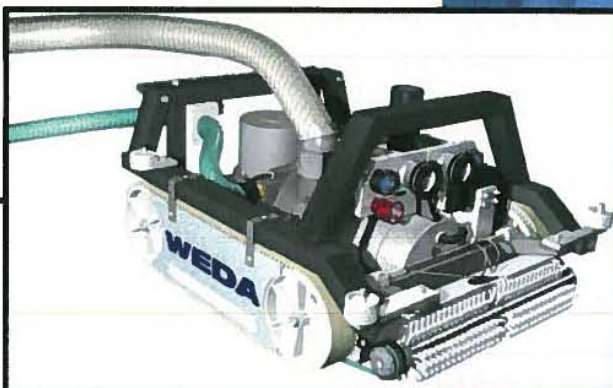

\section{History of Operations}

WEDA WATER INC. is a U.S.-based subsidiary of the Eletta International AG Group, a

Swiss-based conglomerate comprised of a diverse group of companies, including sub-

mersible technologies, electric motors and flow monitors.WEDA WATER INC. has a long-

standing reputation manufacturing robotics equipment in the European market. WEDA WA

TER INC. revolutionary technology has made it the industry choice among commercial reservoir cleaning providers worldwide.

\section{Nuclear Experience}

Yes

\section{Technical Approach}

Using brushes and a powerful submersible pump, VR Systems underwater cleaning units remove sediment and can discharge the waste to an approved location, such as a sanitary sewer, a lagoon or truck. Equipped with lights and video cameras,

the vehicles are controlled with a joystick while referencing monitors with real-time video.

\section{Tank Sizes}

VR-600 - compact and manhole accessible, cleans up to 1,000 sq.ft./hr. and can handle solids up to $.5^{\prime \prime}$ dia.

- VR-800 - larger and more powerful, cleans up to 1,500 sq.ft./hr. and can handle solids up 1.5" dia.

\section{Wet / Dry Application} Wet
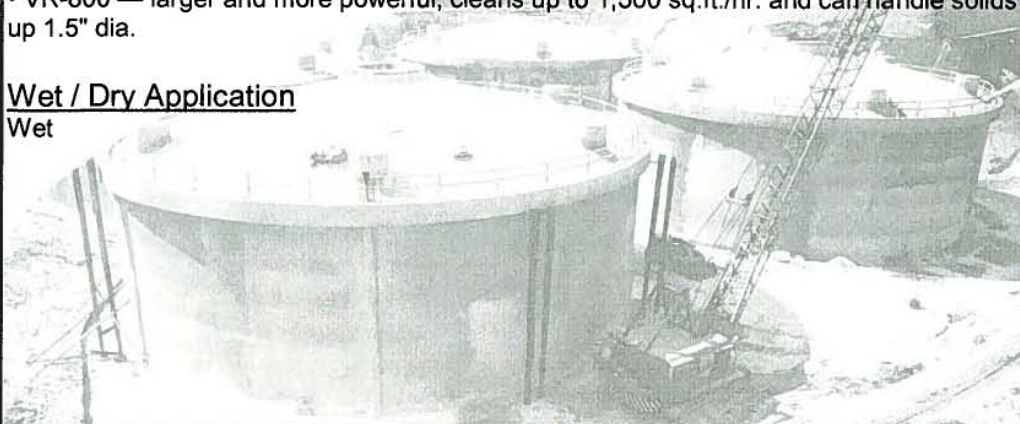

WEDA WATER INC.

978 Antelope Ave, NEAlbuquerque, NM 87122 


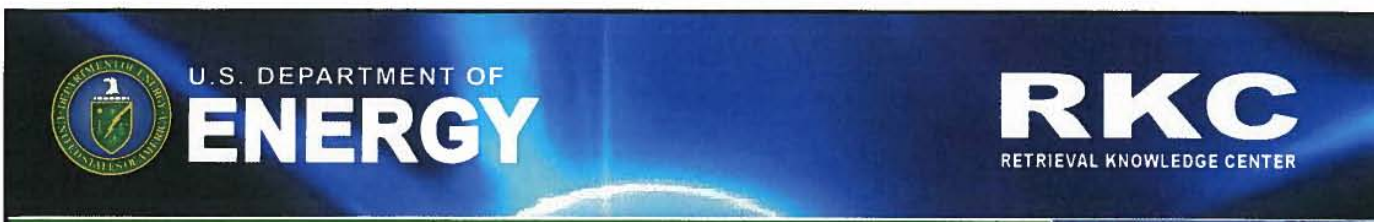

\section{NLB Corporation}

\section{Industries}

Tank Cleaning (Water Reservoirs)

\section{History of Operations}

All of us at NLB hope that the water jetting experience we've acquired over the past 33 years will help you be more productive and more profitable.

\section{Nuclear Experience \\ Yes \\ Technical Approach}

NLB 3750 3-D cleaning heads produce 3-dimensional coverage that thoroughly cleans tank, tote and reactor interiors. They are available in three models, delivering flows of 15 to $80 \mathrm{gpm}$ ( 57 to $302 \mathrm{lpm}$ ) at pressures of up to $13,000 \mathrm{psi}$ ( $896 \mathrm{bar}$ ). Each of these models can be ordered in a heavyduty bronze body, a stainless steel body or a lightweight aluminum body, depending on the application. All rotate from 2 to $40 \mathrm{rpm}$, and feature adjustable rotating speeds to suit the type of build-up being removed.

\section{Tank Sizes}

The Telescopic Lance is used in large vessels and in areas where overhead height is limited. It features external handwheels to extend/retract, incline and rotate the 3-D head as needed, and a custom-designed manway adapter. Standard lance lengths range from $20^{\prime \prime}$ to $295^{\prime \prime}$ to service vessels from $121^{\prime \prime}$ to $334^{\prime \prime}$ in height. Custom-engineered sizes are. also available, as are fully-automated telescopic lances.

\section{Wet / Dry Application} Wet

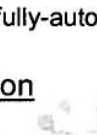




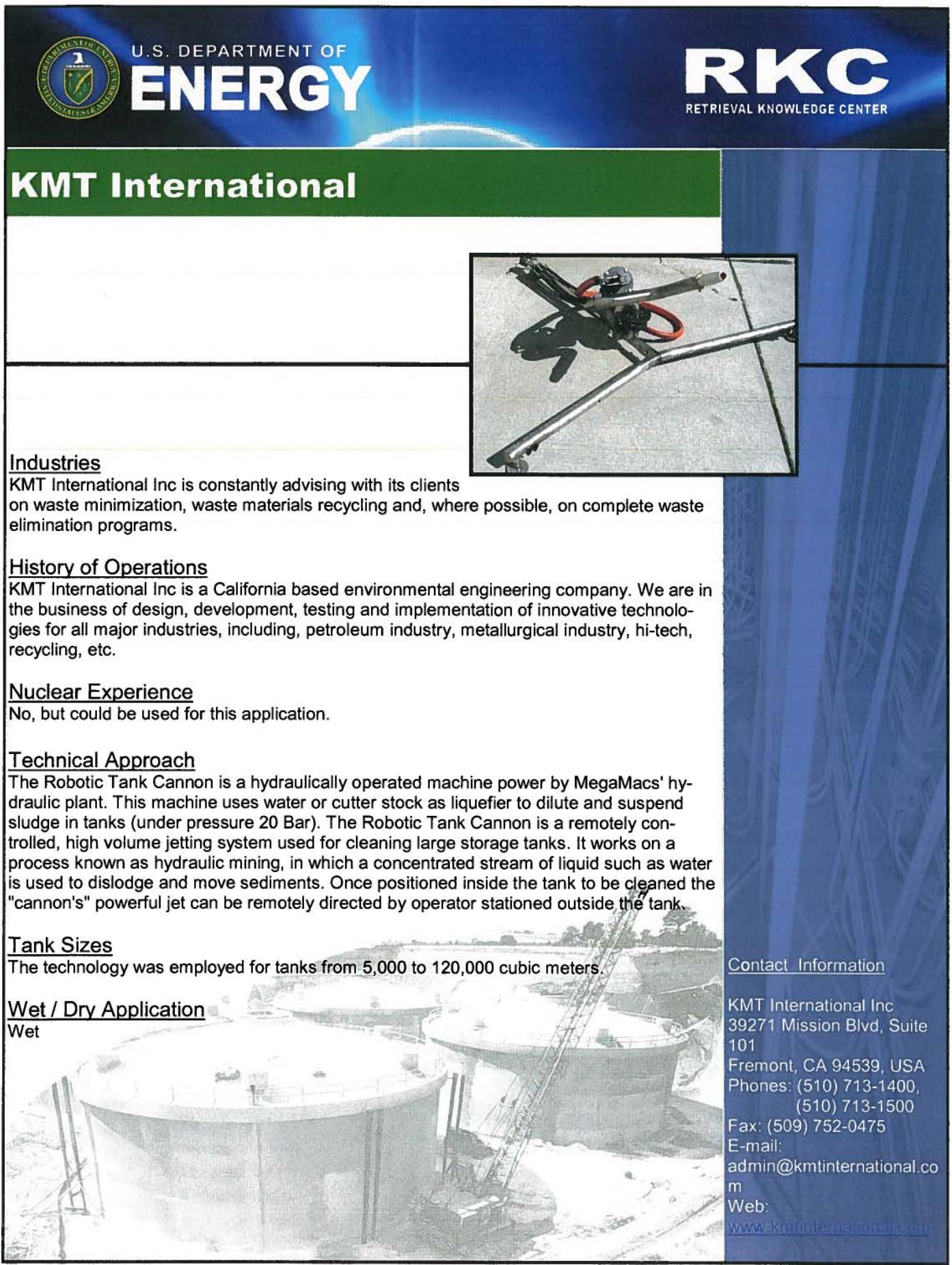




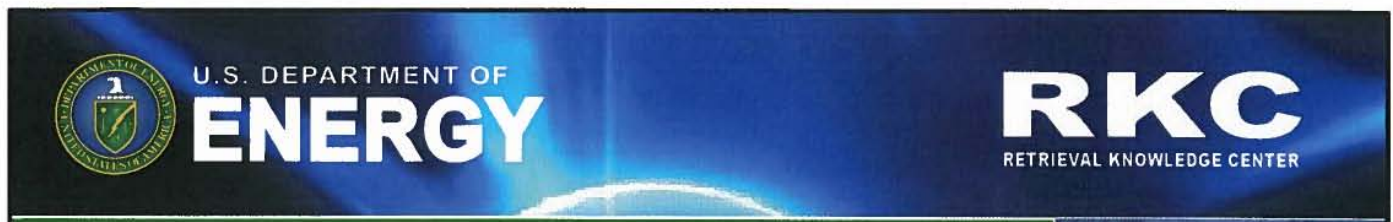

\section{Alfa Laval}

\section{Industries}

Beverages, Biofuels, Biotech and Pharmaciuticals, Chemicals,

Food, HVAC, Machinery, Marine, Metals and minerals, extraction, Metal working,

Oil and gas, Oil refinery, Power, Pulp and paper, Wastewater treatment.

\section{History of Operations}

Gustaf de Laval was a great technical genius whose inventions include the centrifugal separator and the first functional steam turbine. During his lifetime, he registered 92 patents and started 37 companies. In 1883, he and his partner, Oscar Lamm Jr., established the company AB Separator, the forerunner of today's Alfa Laval.

\section{Nuclear Experience}

N/A

\section{Technical Approach}

Separators with high rotation speeds undertake the continuous separation of a wide range of different solids from either one or two liquids. High-speed separators are primarily used for separating fluids.

Due to the centrifugal force in separators, the fluid/particles with the greatest density collect in the outer periphery of the separator bowl. Both fluid phases are then discharged through separate outlets.

\section{Tank Sizes}

The technology was employed for tanks from 5,000 to 120,000 cubic meters.

\section{Wet / Dry Application} Wet

\section{-}

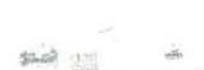

\section{5,000 to 120,000 cubic meters.}

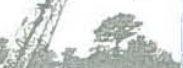

Surrey

GU15 3DN

United Kingdom

Phone: +44 127663383

Fax: +441276685035

Email: gen-

eral.uk@alfalaval.com

Link: http://

local.alfalaval.com 


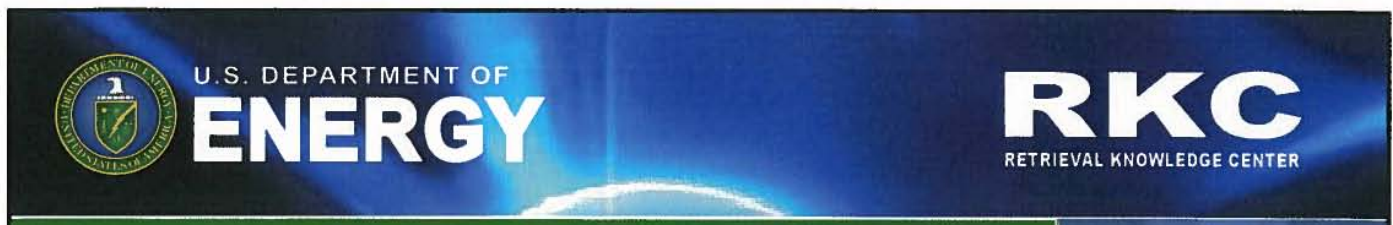

\section{Newalta}

\section{Industries}

Petroleum and waste disposal

\section{History of Operations}

We are leaders in finding better ways to manage waste. The path to our leadership position began in 1993. We had six facilities, $\$ 8$ million in revenue and slightly more than $\$ 1$ million in cash flow.

\section{Nuclear Experience}

N/A

\section{Technical Approach}

The robotic technology allows an operator using a television monitor to clean from outside a vessel. A high-pressure stream of "cutter fluid" mobilizes sludge. Sludge is pumped to a multi-phase separation and purification system. The system separates tank-bottom contents into three streams - solids, recyclable water and high-value oil.

Newalta combines technology and practical innovation for solutions that work. Protecting the environment and recovering more value for our customers

\section{Tank Sizes}

\section{Wet / Dry Application} Wet 


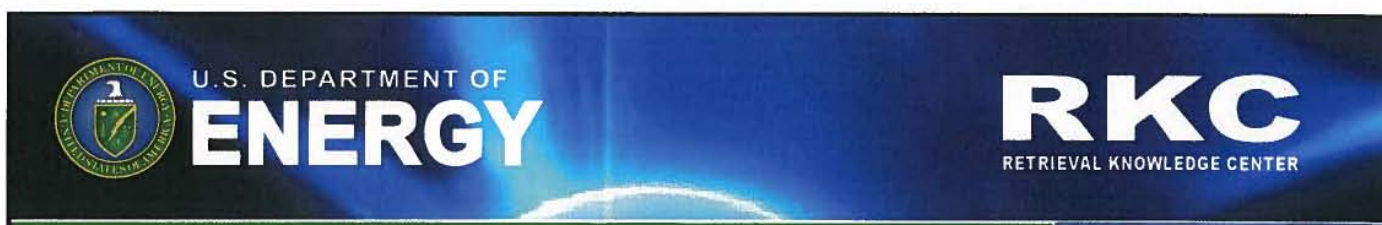

\section{TriStar PetroServ}

\section{Industries}

TriStar has earned the trust of leading companies in refining, petrochemical, pipeline, power generation, pulp and paper, and industrial applications worldwide. Our capabilities range from advanced robotic sludge extraction and centrifugal phase separation to cuttingedge chemical and thermal degassing techniques.

\section{History of Operations}

TriStar was founded in 2002 by a group of industry experts with extensive experience in industrial cleaning, waste management, safety and related disciplines. Following a carefully managed business development plan, TriStar Petroserv has grown from a regional service provider in the U.S. to an leader operating worldwide.

\section{Nuclear Experience}

No

\section{Technical Approach}

TriStar provides clean, gas-free tanks in preparation for API 653 inspections, repairs, product changes, decommissioning and other requirements. We handle tanks of any size or design, with any type of product, including crude oil, fuel oil, decanted slurry oil, slop oil, light end/finished products and more.

TriStar is a leader in applying robotic technology to improve efficiency and enhance safety. TriStar robotics minimize the need for personnel entry, reduce vapor emissions and can eliminate the need to cut door sheets.

\section{Tank Sizes}

Various

\section{Wet / Dry Application} Wet

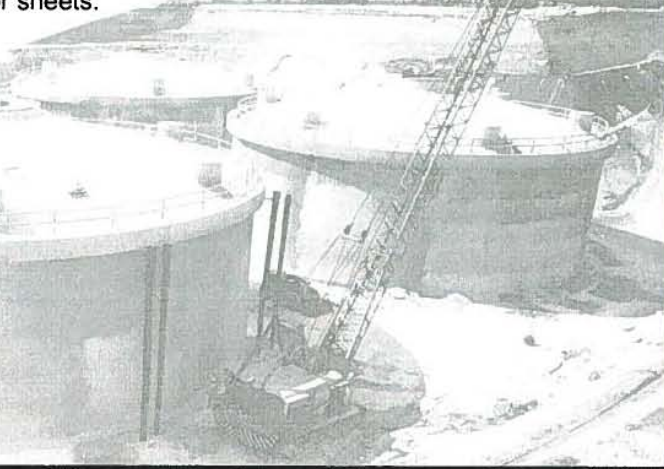




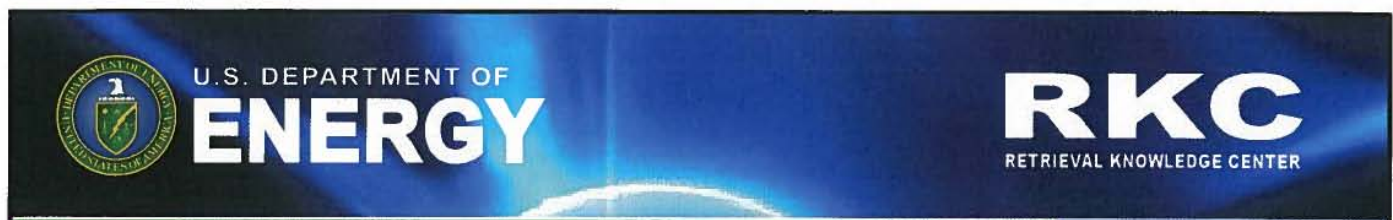

\section{AGI Engineering}

\section{Industries}

Over the past decade, AGI Engineering has produced an impressive list of customers. Ranging from Fortune 500 manufacturers, to industrial machinery manufacturers, to contractors for the Federal Government, AGl's customers are experts in their industries and they expect nothing less than the best in quality, service, and support.

\section{History of Operations}

For the past decade, AGI Engineering has been designing high quality, cutting-edge equipment for the tank cleaning and automation industries. AGI designs and produces custom equipment specifically designed to meet the needs and requirements individual customers applications.

\section{Nuclear Experience \\ N/A}

\section{Technical Approach}

AGI can meet a variety of production and regulatory requirements. Anything from NQA-1 quality control to UL508A electrical panels, to AWS certified welding can be done in house to meet customer specifications and project requirements.

AGI tank cleaning equipment has been used in an array of application to meet very stringent regulations and customer requirements. Every tank is unique and AGI has worked on systems intended to clean everything from small rail cars, to terminal storage tanks, to supertankers. AGI offers an array of tank cleaning products for-any tank-environment. AGl's remote cleaning and processing technologies allow for reduced cleaning time, limited confined space entry, and increased safety.

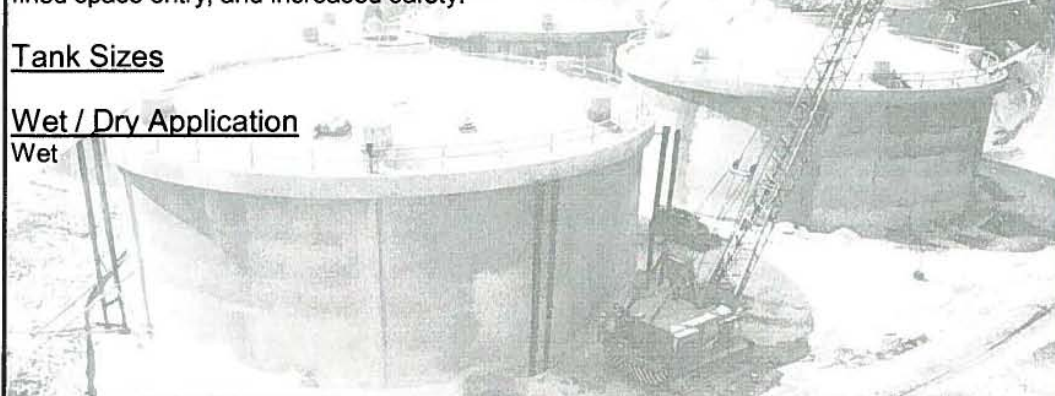




\section{Distribution:}

Savannah River National Laboratory

S. L. Marra, 773-A

W. R. Wilmarth, 773-A

R. L. Minichan, 723-A

J. L. Steimke, 786-5A

Pacific Northwest National Laboratory

M. W. Rinker

K. Airhart

E. J. Berglin 